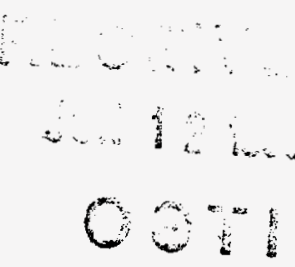

\title{
HYDROGEN PICKUP AND REDISTRIBUTION IN ALPHA-ANNEALED ZIRCALOY-4
}

\author{
B. F. Kammenzind, D. G. Franklin, H. R. Peters, and W. J. Duffin
}

\section{DISCLAIMER}

This report was prepared as an account of work sponsored by an agency of the United States Government. Neither the United States Government nor any agency thereof, nor any of their employees, makes any warranty, express or implied, or assumes any legal liability or responsibility for the accuracy, completeness, or usefulness of any information, apparatus, product, or process disclosed, or represents that its use would not infringe privately owned rights. Reference herein to any specific commercial product, process, or service by trade name, trademark, manufacturer, or otherwise does not necessarily constitute or imply its endorsement, recommendation, or favoring by the United States Government or any agency thereof. The views and opinions of authors expressed herein do not necessarily state or reflect those of the United States Government or any agency thereof. 
HYDROGEN PICKUP AND REDISTRIBUTION IN ALPHA-ANNEALED ZIRCALOYA
B. F. Kammenzind',
D. G. Franklin', H.
H. R. Peters' ${ }^{2}$, and W. J. Dutfin'

'Bettis Atomic Power Laboratory

${ }^{2}$ Knolls Atomic Power Laboratory

Westinghouse Electric Corporation

Martin Marietta Corporation

West Mifflin, Pennsylvania 15122

Schenectady, New York 12301-1072

ABSTRACT: Zircaloy-4, which is widely used as a core structural material in PressurizedWater Reactors (PWR), picks up hydrogen during service. Hydrogen solublity in Zrcaloy-4 is low and hydrides precipitate after the Zircaloy -4 matrix becomes supersaturated with hydrogen. These hydrides embrittle the Zircaloy-4. To study hydrogen plckup and concentration, a postirradiation nondestructive radiographic technique for measuring hydrogen concentration was developed and qualifiod. Experiments on hydrogen pickup were conducted in the Advanced Test Reactor (ATR). Ex-reactor tests were conducted to determine the conditions for which hydrogen would dissolve, migrate, and precipitate. Finally, a phenomenological model for hydrogen diftusion was indexed to the data. This presentation describes the equipments and the model, presents the results of experiments, and compares the model predictions to experimental results.

KEYWORDS: Zircaloys, hydrogen, corrosion, diffusion, hydrogen redistribution, hydrogen solubility

\section{INTRODUCTION}

During service, Zircaloys pickup hydrogen, primarily from hydrogen that is liberated as part of the oxidation of Zircaloy by water (1). Hydrogen in solution will diftuse down a thermal gradient and concentrate in cold regions of Zircaloy components (2). Due to the low solubility of hydrogen In Zircaloys, zirconium hydrides form at relatively low concentrations of hydrogen, espectally on cooling to near room temperature. These hydrides are brittie and at low concentration begin to degrade the mechanical properties of Zircaloys (3). These changes in properties need to be considered in component evaluations. Fundamental data and models that describe hydrogen pickup and redistribution can be used in this evaluation process. To provide the bases for such evaluations, in-reactor and out-of-reactor experiments were conducted to develop a database for a fundamental model that provides insight into the phenomena involved.

The low solublity of hydrogen in zirconium alloys and the detrmental effects of hydrides was recognized in the 1950 s (4) during early development of zirconlum alloye for nuclear application. Under normal conditions the influx of hydrogen in-reactor is quite low. Further, th 


\section{DISCLAIMER}

This report was prepared as an account of work sponsored by an agency of the United States Government. Neither the United States Government nor any agency thereof, nor any of their employees, make any warranty, express or implied, or assumes any legal liability or responsibility for the accuracy, completeness, or usefulness of any information, apparatus, product, or process disclosed, or represents that its use would not infringe privately owned rights. Reference herein to any specific commercial product, process, or service by trade name, trademark, manufacturer, or otherwise does not necescarily constitute or imply its endorsement, recommendation, or favoring by the United States Government or any agency thereof. The views and opinions of authors expressed herein do not necessar. ily state or reflect those of the United States Government or any agency thereof. 
difiuses rapidly in the Zircaloy matrix and the hydride does not form at the corroding surface and propagate into the metal as does the oxide. Rather hydrides precipitate heterogeneously as delta hydride, $\mathrm{Zr}_{2} \mathrm{H}_{3}$, throughout the metal at sites that can best accommodate the seventeen-percent volume increase on formation of the hydride. Due to the protective nature of zirconium oxide, corrosion and hydrogen pickup are limited. As long as the environment is not too reducing, the only hydrogen pickup in the metal is from the corrosion process (5). Therefore, hydrogen is not a concern to clad integrtty under normal operating conditions, at least until much corrosion has occurred or hydrogen has concentrated in cold regions.

One of the first modes of fuel rod fallure is commercial power reactors was from hydride blisters, which consisted of a high concentration of hydrides in a local cladding reglon (6). Hydride blisters formed either from internal molsture in the fuel rod, e.g., moisture in the fuet pellet open porosity, or from coolant entering through fuef-cladding defects. Hydride fallures were almost eliminated in the 1970 s by special drying methods for fuel pellets and by reductions in defects of other types.

Performance of Zrcaloy-clad fuel rods has been excellent since 1980 (7). However, isolated instances of hydride fallures have occurred. Steep local temperature gradients may have caused concentration of hydrogen in cladding on PWR tuel rods (8). These concentrations of hydrides may have been sufficient to embrittle the Zrcaloy 4 metal and promote clad cracking. More recently, use of zirconium iners on fuel cladding may have promoted both hydrogen pickup in defected fuel rods, due to the relatively poor corrosion resistance of zirconium liners, and high stresses from the liner volume expansion as it oxidizes (9-11). An intermediate step may be the preferential hydride formation in the zirconium liner over that of the adjacent Zircaloy-2, despite the higher liner temperature, due to the lower strength of the liner (Figure 14 of Reference 10). Hydrides form preferentially in regions of low strength due to the volume expansion during hydride formation (12). This expansion may increase stresses in the Zircaloy-2 prior to full liner oxidation. Subsequent oxddation of the liner removes evidence of this step. This failure mode llistrates the complicated nature and importance of hydrogen dittusion and hydride formation. Understanding hydrogen behavior becomes more Important as fuel bumups are increased, which results in increased corrosion and hydrogen pickup (13).

Fundamental experiments and modeling of diffusion kinetlcs were reported during early development of zirconium alloys for nuclear applications. Appropriate references are provided below in the dlscussion of the results presented herein. Recent work primarily addressed hydrogen in Zr-2.5Nb pressure tubes, as reported by Canadlan researches (5, 14- 
17. These experiments are characterized by studies by hydrogen concentration profiles rather than bulk hydrogen pickup measurements. Little recent work on Zircaloys has been reported. These data and associated models are required to predict the pickup, movement, and precipitation of hydrogen. As shown by the discussion above on the impact of hydrogen on fuel performance, such a capability is important if it can be used to avoid designing and operating fuel elements in a region where large concentrations of hydrides and stresses develop.

\section{Hydrogen Pickup}

\section{Experimental}

Hydrogen pickup was measured on alpha-annealed Zicaloy 4 coupons that were Irradiated in the Advancod Test Reactor (ATR) at $310^{\circ} \mathrm{C}\left(590^{\circ} \mathrm{F}\right.$ and $360^{\circ} \mathrm{C}\left(680^{\circ} \mathrm{F}\right)$. A hydrogen overpressure is maintained in the cooling water to control the oxygen level in the coolant. Under normal conditions this molecular hydrogen does not act as a hydrogen source as the oxdde film is essentially impervious to the molecule. The source of the hydrogen entering the Zrcaloy is that produced in the corrosion reaction. A nondestructive method of measuring hydrogen content was developed and qualified. This method measured the neutron attenuation by absorbed hydrogen as a neutron beam passed through a specimen (Figure 1). A neutron beam with a white nolse spectrum was filtered by passing It through indium-cadmium material. This removed most neutrons with energles that activated indium atoms, resulting in the spectrum shown in Figure 1 as the incident notched spectrum. Passing this beam through a thin foll of indium (in Detector $\left(D_{1}\right)$ in Figure 1) activated this foll in proportion to the remaining number of neutrons at the indium activation energles. This foll was counted to produce the signal value $D_{1}$. The neutron beam then passed through the Zircaloy-4 sample. The neutrons interacted with hydrogen atoms in the Zircaloy-4, which reduced the energy of many of the neutrons. This neutron scattering resulted in many neutrons having their energies decreased to the energy bands for indium activation. This new neutron beam energy spectrum is shown in Figure 1 as the moderated notched spectrum. The moderated beam passed through another indium foll in detector $\left(D_{2}\right)$ in Figure 1) and activated the indium in proportion to the numbers of noutrons at the indium energles. This foil was counted to determine $D_{2}$. The relative difference between $D_{2}$ and $D_{1}$ was proportional to the amount of hydrogen in specimen, $\left(D_{2}-D_{1}\right)+D_{1}$. The attenuation of the beam was calibrated to the hydrogen content of Zircaloy-4 by the use of standards. In addition, each set of specimens included a standard with a known concentration of hydrogen. Since the method was nondestructive, interim measurements were made on coupons using an on-site neutron beam. This allowed the hydrogen plckup of Individual samples to be followed as a function of radiation exposure. Out-of-reactor 
hydrogen pickup was measured after autoclave exposure by destructive hot vacuum extraction to obtain reference data.

\section{Results}

Out-of-reactor reference pickup data Zircaloy-4 coupons from three ingots are shown in Figure 2 for $316^{\circ} \mathrm{C}$ exposure. Autoclave water was degassed and delonized at pH 7 with a resistivity above 1 million ohm centimeters. Pressure was held above that for saturation at $316^{\circ} \mathrm{C}$, about $10.65 \mathrm{MPa}$. Similar in-reactor plckup data are shown in Figures 3 and 4 for exposure at $360^{\circ} \mathrm{C}$ and $310^{\circ} \mathrm{C}$, respectively, for three neutron flux levels: high flux or $\phi>$ $10^{18} \mathrm{n} / \mathrm{m}^{2} / \mathrm{sec}^{\circ}$ medium flux or $10^{18} \mathrm{n} / \mathrm{m}^{2} / \mathrm{sec}>\phi>10^{17} \mathrm{n} / \mathrm{m}^{2} / \mathrm{sec}$, and low fiux or $\phi<$ $10^{17} \mathrm{n} / \mathrm{m}^{2} /$ sec. The data are listed in Table 3 for autoclave exposures, and Table 4 for inreactor exposures. Table 5 lists the chemistry of the Zrcaloy 4 used in the testing. To determine if the hydrogen plckup was correlated with sample oxldation, the measured hydrogen content was plotted as a function of measured oxygen concentration, as determined by weight-galn measurements and as shown in Figure 5. This suggested that most of the hydrogen absorbed during service was from the oxidation. Further, if supported use of a factor to estimate hydrogen pickup from measured or predicted oxidation. In general, the hydrogen plckup is correlated to the oxddation. Above $1000(\mathrm{mg} / \mathrm{sq} \mathrm{dm})$ the plckup ratio $(\Delta \mathrm{H} / \Delta \mathrm{O})$ tends to deviate in both directions from the average value. This is due to a sensitivity of the hydrogen pickup ratio $(\Delta H / \Delta O)$ to temperature and fuence as suggested in Figure 6.

\section{Hydrogen Content of Oxjde Films}

\section{Experimental}

The hydrogen concentration in the oxide film may be different from the hydrogen concentration in the Zircaloy 4 metal. Several studies have shown this to be the case (14, 18). High or low hydrogen concentrations in the oxjde can have an impact on interpretation of hydrogen measurements to determine $\Delta V / \Delta O$ ratios and hydrogen migration. To determine the impact of this effect, Secondary lon Mass Spectroscopy (SIMS) was used to determine the concentration distribution through the oxide and metal of an autoclave Zircaloy-4 specimen. The hydrogen distribution is shown in Figure 7, In which hydrogen is uniformly dispersed in the oxide and concentrated in hydrides in the metal.

To quantify the hydrogen concentrations in the oxide and metal, autoclaved and inreactor corrosion coupons were tested for hydrogen concentration, with and without the

\footnotetext{
All fluxes are for E> $1 \mathrm{MeV}$.
} 
oxde film, as shown in Figure 8. The oxide was removed with silicon carbide paper or with a Dremel tool. Both were used under flowing water to avoid heating the material. The results from autoclave specimens, tested at $360^{\circ} \mathrm{C}, 19.2 \mathrm{MPa}$ in deionized degassed water, are given in Table 1. The results from in-reactor testing are shown in Figure 9 and 10. Out-of-reactor samples exhibited similar hydrogen concentrations in the oxide and metal. However, in reactor samples had hydrogen concentrations in the oxjde much greater than that in the metal. Figures 9 and 10 show how the In-reactor hydrogen concentrations in the oxide varied with fast fluence (>1 Mev) and oxide thickness. There is considerable scatter in both and no sign of a simple dependence of thickness, fluence, or fast flux. The hydrogen content of the oxjde saturated quickly and thereafter was independent of oxide thickness, fluence, or thx. The original coupon thickness was about $1000 \mathrm{~mm}$. Since the hydrogen concentration in the

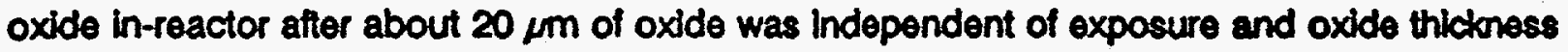
(Figures 9 and 10), the relative amounts of hydrogen in the oxide and metal depended on the relative volumes of oxide and hydride as well as the amount in the metal, which does depend on exposure. In thin coupons the hydrogen in the oxide can be a significant fraction of the total hydrogen content of the oxidized coupon.

\section{Hydrogen Migration in Zrealoy-4}

Hydrogen migration down temperature gradients results in a concentration of hydrogen in hydrides when the metal hydrogen concentration excoeds solubility in the cold reglons of a zirconium alloy. However, hydrogen migration models can not be based on equilibrium, principally because volume mismatch between metal and hydride densities results in lattice distortion on precipitation. The energy required to induce this distortion delays precipitation until the metal hydrogen concentration exceeds the equilibrium concentration. A model for the migration of hydrogen in Zircaloy (27), modified to accommodate a difference in the solubility limits for dissolution and precipitation of the hydride, was used to describe the process. The metal concentration at equilibrium between metal and hydrides was used for dissolution of the hydrides, $\mathbf{C}_{\boldsymbol{e q}}$. Precipitation of hydrides requires a supersaturation of hydrogen relathe to a solubility limit for precipltation $C_{P T}$, which is somewhat higher than $C_{\omega \cdot}$ When the hydrogen concentration in solution in the metal is between $\mathbf{C}_{\infty}$ and $\mathbf{C}_{\mathrm{PT}}$, hydride will not precipitate and existing hydrides will not grow. Hydrides dissolve in equilibrium with the metal matrix at the equilibrium concentration $C_{\infty}$. The model is summarized in Table 2. Qualification experiments were designed to confirm the model and to provide data for indexing constants. 


\section{Experimental}

To determine the solid-solution diffusion coefficient, diffusion couples were made by precharging haff of the sample (Figure 11) and then annealing the sample at temperatures between $260^{\circ} \mathrm{C}$ and $482^{\circ} \mathrm{C}$, for 3.9 days at $427^{\circ} \mathrm{C}$ (Figure 12). The material used was that of ingot $B$ in Table 5. Specimens were precharged with hydrogen by gaseous equilibration when the desired hydrogen distribution was uniform. Specimens where only a portion was to be precharged were cathodically precharged by partial immersion in $1 \mathrm{~N}$ sulturic actd, poisoned against hydrogen recombination with 0.25 grams per liter of sodlum arsenate. The current was $100 \mathrm{ma} / \mathrm{cm}^{2}$ and the temperature was $80^{\circ} \mathrm{C}$.

\section{Results}

The diffusion coefficients determined from these studies are shown in Figure 13, and are in reasonable agreement with the results of Kearns (19) but below results reported by Somemo (20), Sawatzky $(21,26)$, and Mallett and Albrecht (22). Data in the Hterature have demonstrated that a hysteresis exists in the precipitation and dissolution solvi (Figure 14).

\section{Hydrogen Dissolution}

Experimental

To determine the hydride dissolution solvus, similar diffusion couples were made but the two sides were allowed to come to equilibrium at each temperature (Figure 15). The hydride dissolution solvus as a function of temperature was determined by measuring the postanneal hydrogen concentration of the initially uncharged haff of the samples.

\section{Results}

The results are shown in Figure 16 and compared to the results of other researches. The results agree well with those of Sawatzky (21), Slattery (23), and Kearns (24) who used two different techniques. They do not agree with the results of Erickson and Hardie (25). Based on the agreement of three Investigators, it is concluded that the data presented heren accurately refiect dissolution of zirconlum hydrides in Zircaloy. In addition, there appears to be no differenco between the dissolution solvi for Zircaloy-2 and Zircaloy-4.

\section{Hydrogen Precipltation}

\section{Experimental}

To determine the hydride precipitation solvus, uniformly-hydrogen-charged specimens were annealed in a temperature gradient that varied inearly and monotonically from one end of each sample to the opposite end (Figure 17). Hydrogen procharge levels were chosen such that the entre sample was in the single-phase state at the boginning of the test. The cold ends of each sample were held at etther $260^{\circ} \mathrm{C}, 316^{\circ} \mathrm{C}, 371^{\circ} \mathrm{C}$, or $427^{\circ} \mathrm{C}$ and the 
temperature gradients were either $6.6^{\circ} \mathrm{C} / \mathrm{mm}$ or $8.7^{\circ} \mathrm{C} / \mathrm{mm}$. Hydrogen diffuses down the temperature gradient until the concentration gradient provides sufficient counter driving force to balance the thermal migration. At equilibrium the hydrogen concentration in solution in the Zircaloy matrix will have the distribution

$$
C(T)=C_{0} \exp \left(Q^{*} / R T(x)\right) .
$$

This will be the temperature and spatial distribution, as $T=T(x)$, of the total or measured concentration when the total concentration is below that required for precipltation of the hydride. When the total concentration is above $C(T)$ there has been precipitation. For example, the hydrogen concentration profile when a profile close to $\mathrm{C}(\mathrm{T})$ has developed except at the cold end is shown in Figure 18. In this case, the hydrogen concentration at the cold end of the specimen is well above $\mathrm{C}(\mathrm{T})$, Indicating precipltation. The concentration $\mathrm{C}_{\infty}$ for dissolution of the hydride is also shown by the dashed line, which at $371^{\circ} \mathrm{C}$ is well below that for precipitation, $\mathrm{C}_{\mathrm{pT}}$.

\section{Results}

The results from each test are shown in Figure 19, where they are compared with literature data. At temperatures above $316^{\circ} \mathrm{C}$ there is reasonable agreement among the results of the three literature references and the data reported herein. Our data may have a slightly lower slope. At $260^{\circ} \mathrm{C}$ the precipitation concentration reported herein ts greater than that reported by Erickson and Hardie or by Slattery.

\section{Discussion}

The heat of transport, $Q^{*}$ in equation 1 in Table 2, was determined for each sample from the slopes of $\log ([\mathrm{H}])$ vs inverse temperature, as shown in Figure 18 for a sample with a cold end at $371^{\circ} \mathrm{C}$. The results are shown in Flgure 20 . The reprecipitation constant, $a$ in equation 2 in Fable 2, determines the reprecipitation kineties in this model and can be determined by measuring the surface and midplane precipitated hydrogen concentration, as shown in Figure 21. Samples were corroded in concentrated lithlated water at temperatures between $288^{\circ} \mathrm{C}$ and $360^{\circ} \mathrm{C}$ in autoclaves at pressures high enough to maintain temperature below the saturation temperature, $2.79 \mathrm{MPa}$ and $18.65 \mathrm{MPa}$, respectively. The results are shown in Figure 22.

This model for hydrogen diffusion was benchmarked to several out-of-reactor experiments. One sample (Figure 23) was placed in a steep temperature gradtent and the other sample (Flgure 24) was placod in a shallow temperature gradient. After annealing, the 
samples were sectioned and hydrogen concentrations were measured by hot vacuum extraction. The resulting hydrogen-concentration profiles are shown in Figures 23 and 24 , along with the temperature profiles and the model predictions of the hydrogen concentrations. The model predicts the observed concentrations adequately for the sample with the steep temperature gradient (Figure 23) but not for the sample with the shallow temperature gradient, for which the model over predicts hydrogen concentration in the colder regions. The most likely cause of the model misprediction is hydrogen trapping at lattice defects or a second phase. Trapping would result in higher required driving forces, 1.e., thermal gradients, to redistribute the hydrogen.

For application to fuel designs, the above migration model must be combined with a model for hydrogen plckup. Based on the discussion in the previous section, the plckup model must properly refiect the relative amounts of hydrogen in the metal and oxlde.

\section{Conclusions}

To describe the embrittlement of zirconium alloys due to formation of hydrides, the following aspects must be understood: hydrogen pickup rate, holdup of hydrogen in the oxide, diffusion rates in a matrix with hydrogen traps, hydrogen concentration in the metal for hydride dissolution, and metal hydrogen concentration for hydride precipltation and dissolution. The experiments described provide qualification data for each aspect, although additional data are needed in some areas, e.g., no holdup of hydrogen in the oxide. The model described is adequate for steep gradients but overpredicts hydrogen redistribution for shallow temperature gradients. This deficlency is thought to be due to the lack of a description of hydrogen trapping at lattice defects, l.e., the model should refiect the binding energies between the hydrogen strain field and lattice defect strain fields.

\section{References}

1. Cox, B, "Oxidation of Zirconium and its Alloys", Advances in Corrosion Sclenco and Technology, Volume 5, 1976, pp. 173-391.

2. Markowitz, J. M., "The Thermal Diffusion of Hydrogen in Apha-Delta Zrcaloy-2", Trans. Met. Soc. AIME, 221 (1961), 819-824.

3. Kreyns, P. H. Bourgeois, W. F., Charpentier, P. L, White, C. J., Kammenzind, B. F., and Franklin, D. G., "Lfetime Embrittlement of Reactor Core Materials", WAPD-T3046, ASTM STP (published elsewhere in this STP).

4. Mudge, W. L Jr., "Effect of Hydrogen on the Embrittement of Zrconlum and Zrconium Tin Alloys", Zrconlum and Zrconlum Alloys, pub. Am. Soc. for Metals, Cleveland, Orio, 1953, pp. 146-167. 
5. Emoselhi, M. B., Warr, B. D., and Mclntyre, S., 'A Study of the Hydrogen Uptake Mechanism in Zirconium Alloys, 'Zirconlum in the Nuclear Industry, Tenth International Symposium, ASTM STP 1245, A.M. Garde and E. R. Bradley, Eds., American Society for Testing and Material:. Philadelphia, PA, USA, 1994 pp. 62-79.

6. Proebstle, R. A., ot al., "The Mechanism of Defection of Zircaloy-Clad Fuel Rods by Internal Hydriding", Proceedings of Joint Topical Meeting on Commercial Nuclear Fuel Technology Today, Toronto, Canada, April 28-30, 1975, 75-CNA/ANS-100, pp. 2-15 to 2. 34

7. Preble, E. A. et. al., "Fuel Periormance Annual Report for 1990 ", Pactic Northwest Laboratory, Richland, WA 99352, USA, NUREG/CR-3950, PNL-5210, v.8, Nov. 1993.

8. R. Yang, O. Ozer, and H. H. Kepler, "Fuel Performance Evaluation for EPRI Program Planning", International Toplcal Meeting on LWR Fuel Performance, Avignon, France, $4 / 21 \cdot 24 / 91$, pp. 2.58 , to 2.71 .

9. Schrire, David et. al, "Secondary Defect Behavior in ABB BWR Fuel", Procoedings of the 1994 International Meeting on Uight Water Reactor Fuel Performance, West Palm Beach, FL, USA, Aprll 17-21, 1994, pp. 398-409.

10. Armijo, J. S., "Periormance of Failed BWR Fuer", Proceedings of the 1994 International Meeting on Light Water Reactor Fuel Performance, West Palm Beach, FL, USA, April 17. 21, 1994, pp. 410-422.

11. Yang, Rosa $L$ et al., "EPRI Failed Fuel Degradation R\&D Program", Procoedings of the 1994 International Meeting on Light Water Reactor Fuel Performance, West Palm Beach, FL, USA, April 17-21, 1994, pp. 435-446.

12. Puls, M. P., "Effects of Crack Tip Stress States and Hydrido-Matrix Interaction Stresses on Delayed Hydride Cracking", Metallurgical Transactions A, 21A, (1990) pp. 2905-2917

13. Baur, Karl, et al., "Fuel Behavior in High Performance PWRs", Proceodings of the 1994 International Meeting on Lght Water Reactor Fuel Performance, West Palm Beach, FL, USA, April 17-21, 1994, pp. 22.30.

14. Warr, B. D., et al., "Oxide Characteristics and their Relationship to Hydrogen Uptake in Zirconlum Alloys', Zirconium in the Nuclear Industry, Ninth International Symposium, ASTM STP 1132, C. M. Eucker and A. M. Garde, Eds., American Society for Testing and Materlals, Philadelpha, PA, USA, 1991, pp. 740-756.

15. Laursen, T., et al., "Hydrogen Ingress Into Oxidized Zr-2.5Nb", J. Nud. Mater., 209, (1994) pp. $52-61$.

16. Laursen, T., Lesile, J. R., and Tapping, R. L, "Corrosion of Zr-2.5 wt\% Nb Pressure Tube Material in $\mathrm{D}_{2} \mathrm{O}$ Steam: Deuterim Depth Distributions Measured by Nuclear Reaction Analysis", J. Nucl. Mater., 182, (1991) pp. 151-157.

17. Laursen, T., Leslie, J. R., and Tapping, R. L., Deuterlum Depth Distributions in Oxddized Zr-2.5 wt \% Nb Measured by Neutron Reaction Analysis, Joumal of the Less-Common Metals, 172-174, (1991) pp. 1306-1312. 
18. Woolsey, I. S. and Morris, J. R., 'A Study of Zircaloy-2 Corrosion in High Temperature Water Using lon Beam Methods", Paper 178, presented at the March 3.7, 1980 Conference of the NACE, Chicago, ILL, also in Corrosion 37 (1981), pp. 575-585.

19. Keams, J. J., 'Dittusion Coefficient of Hydrogen in Alpha Zirconium, Zircaloy-2, and Zircaloy-4", J. Nuct. Mater., 43 (1972) pp. 330-338.

20. Someno, M., "Determination of the Solubility and Diffusion Coefficient of Hydrogen in Zirconium", Nihon Kinzoku Gakkaishl 24 (1960) pp. $249-253$.

21. Sawatzky, A., The Diffusion and Solubility of Hydrogen in the Alpha Phase of Zircaloy2', J. Nuclear Mater. 2, (1960) pp. 6268.

22. M. W. Mallet and W. M. Abrecht, "Low Pressure Solubility and Diffusion of Hydrogen in Zirconium', J. Electrochemical Soc., 104 (1957) pp. 142.

23. Slattery, G. F., The Terminal Solubility of Hydrogen in Zrconlum Alloys between 30 and $400^{\circ} \mathrm{C}$, J. Inst. Metals, 95 (1967) pp. 43-47.

24. Kearns, J. J., Terminal Solubility and Partitioning of Hydrogen in the Alpha Phase of Zirconium, Zircaloy-2 and Zircaloy-4", J. Nuclear Mater. 22 (1967) pp. 292-303.

25. Erickson, W. H. and Hardie, D., The Influence of Alloying Elements on the Terminal Solubility of Hydrogen in a-Zirconium;. J. Nuclear Mater. 13 (1964) pp. 254-262.

26. Sawatzky, A. and Wilkins B.J.S., "Hydrogen Solubility in Zrconium Alloys Determined by Thermal Diffusion", J. Nuclear Mater. 22 (1967) pp. 304-310.

27. Marino, G. P., 'A 2-Dimensional Computer Program for Migration of Interstitial Solutes of Finite Solubility in a Thermal Gradient", WAPD-TM-1157, June 1974.

28. Marino, G. P., "Hydrogen Supercharging in Zrcaloy", Mater. Sc. Eng., 7 (1971) Pp. 335 341.

\section{Acknowledgement}

This work was supported by DOE contract DE-AC11-93PN38195.

\section{NOTICE}

This report was prepared as an acoount of work sponsored by the United States Govermment. Neither the United Statee, nor the United States Department of Energy, nor any of their employees, nor any of their contractors, eubcontractore, or their employeen, makes any warranty, express or implied, or assumes any logal tability or responsibitity for the accuracy, completeness or usetulnese of any information, apparatu, product or proceses dieclosed, or represents that the weo would not infringe privately anned righte. 
TABLE 1 - Hydrogen Retained in Oxide Autoclaves Samples

\begin{tabular}{cccccc}
\hline & & & \multicolumn{2}{c}{ Hydrogen Content (ppm) } \\
\cline { 4 - 5 } Sample & Thickness & Wh. Gain & Oxide On* & Oxide Off** \\
\hline 1 & $890 \mu \mathrm{m}$ & $642 \mathrm{mg} / \mathrm{dm}^{2}$ & $669 \pm 11$ & $660 \pm 7$ \\
2 & $890 \mu \mathrm{m}$ & $616 \mathrm{mg} / \mathrm{dm}^{2}$ & $751 \pm 9$ & $750 \pm 4$ \\
3 & $1,550 \mu \mathrm{m}$ & $1091 \mathrm{mg} / \mathrm{dm}^{2}$ & $574 \pm 8$ & $589 \pm 6$ \\
4 & $1,450 \mu \mathrm{m}$ & $893 \mathrm{mg} / \mathrm{dm}^{2}$ & $558 \pm 10$ & $552 \pm 6$ \\
5 & $1,650 \mu \mathrm{m}$ & $204 \mathrm{mg} / \mathrm{dm}^{2}$ & $177 \pm 3$ & $185 \pm 6$ \\
6 & $2,890 \mu \mathrm{m}$ & $1052 \mathrm{mg} / \mathrm{dm}^{2}$ & $337 \pm 3$ & $338 \pm 3$ \\
\hline
\end{tabular}

* Measurements of hydrogen concentration in both metal and oxide.

** Measurements of hydrogen concentration in metal only. 
TABLE 2 - Model Used for the Migration of Hydrogen

1. Hydrogen diffuses through the alpha ( $(\mathrm{cp})$ phase in response to temperature and solid solution concentration gradients.

$$
\overrightarrow{\mathrm{J}}=-D \nabla C-\frac{D Q C}{R T^{2}} \nabla T
$$

D - Diffusion coefficient of hydrogen through a Zlrcaloy

C - Solld solution concentration of hydrogen in a Zrcaloy

$Q^{\circ}$ - Heat of Transport

T - Temperature

II. The rate of change in hydrogen concentration at a point is

$$
\frac{8 C_{T}}{8 t}=-\nabla \cdot J
$$

The rate of change in hydrogen concentration solid solution in the a Zircaloy is

$$
\begin{aligned}
& \frac{\partial C}{\partial t}=-\nabla J-\alpha^{2}\left(C-C_{P T}\right), C>, C_{T T} \\
& \frac{\partial C}{\partial t}=\frac{8 C}{\partial t}=-\nabla \cdot J, C<C_{P T} \text { or }
\end{aligned}
$$

$\frac{8 C}{8 t}=0, C=C_{\infty q}$ if hydrides are dissolving.

$C_{T}=$ total hydrogen concentration

$C_{P T}=C_{P T O} \exp \left(-Q_{P} / R T\right)$ concentration for precipitation

$C_{\infty}=C_{\infty \infty \rho} \exp \exp \left(-Q_{\infty \varphi} / R T\right)$ concentration for dissolution

$\sigma^{2}=\alpha_{0}^{2} \exp \left(-2 Q_{0} / R T\right)$ fitted rate parameter for precipltation 
TABLE 3 - Weight Gain of Alpha-Annealed Zircaloy-4 Exposed at $316^{\circ} \mathrm{C}\left(589^{\circ} \mathrm{K}\right)$ in Autoclave $(\mathrm{mg} / \mathrm{dm} \mathrm{sq})$ *

\begin{tabular}{|c|c|c|c|c|c|}
\hline SPEC & INGOT & DAYS & aWTGN & HWTGN & $\mathrm{H} / \mathrm{O}$ \\
\hline 1 & A & $\cdot 1470.0$ & 95.30 & 5.60 & 0.0588 \\
\hline 2 & A & 854.0 & 49.70 & 2.30 & 0.0463 \\
\hline 3 & A & 910.0 & 5260 & 2.40 & 0.0456 \\
\hline 4 & A & 1078.0 & 6320 & 2.00 & 0.0443 \\
\hline 5 & A & 266.0 & 21.10 & 0.90 & 0.0427 \\
\hline 6 & $\mathbf{A}$ & 1276.0 & 76.70 & 3.30 & 0.0430 \\
\hline 7 & $A$ & 7980 & 48.00 & 2.00 & 0.0417 \\
\hline 8 & A & 1470.0 & $\$ 5.00$ & 3.50 & 0.0411 \\
\hline 9 & $A$ & 742.0 & 47.10 & 1.90 & 0.0400 \\
\hline 10 & A & 154.0 & 18.50 & 0.70 & 00583 \\
\hline 11 & A & 350.0 & 2600 & 1.00 & 0.0385 \\
\hline 12 & A & 686.0 & 40.50 & 1.50 & 0.0370 \\
\hline 13 & A & 22267.0 & 155.40 & 5.50 & 0.0054 \\
\hline 14 & $A$ & 518.0 & 27.00 & 1.10 & 0.0094 \\
\hline 15 & $A$ & 169.0 & 111.40 & 350 & 0.0314 \\
\hline 16 & 8 & 742.0 & 38.30 & 1.70 & 0.044 \\
\hline 17 & $B$ & 910.0 & 52.90 & 2.10 & 0.0697 \\
\hline 18 & B & 265.0 & 23.10 & 0.00 & 0.0050 \\
\hline 19 & B & 1694.0 & 116.40 & 4.50 & 0.0387 \\
\hline 20 & B & 854.0 & 52.00 & 2.00 & 0.0385 \\
\hline 21 & B & 1078.0 & 62.60 & 2.40 & 0.0083 \\
\hline 22 & B & 798.0 & 4820 & 1.00 & 0.0373 \\
\hline 23 & B & 1278.0 & 81.80 & 3.00 & 0.0058 \\
\hline 24 & B & 1470.0 & 9750 & 3.40 & 0.0349 \\
\hline 25 & 8 & 518.0 & 29.00 & 1.00 & 0.0345 \\
\hline 26 & B & 1470.0 & 87.60 & 3.30 & 0.0338 \\
\hline 27 & B & 154.0 & 21.30 & 0.70 & 0.0020 \\
\hline 28 & B & 350.0 & 28.10 & 0.90 & 0.0320 \\
\hline 29 & B & 2267.0 & 15070 & 4.00 & 0.0005 \\
\hline 30 & C & 910.0 & 53.50 & 2.10 & 0.0390 \\
\hline 31 & C & 1470.0 & 92.30 & 3.60 & 0.0300 \\
\hline 32 & C & 1078.0 & 60.70 & 2.30 & 0.0379 \\
\hline 33 & $c$ & 798.0 & 4920 & 1.80 & 0.0056 \\
\hline 34 & C & 1470.0 & 81.50 & 3.40 & 0.0372 \\
\hline 35 & C & 1024.0 & 106.50 & 4.00 & 0.0377 \\
\hline 36 & C & 2267.0 & 147.70 & 5.40. & 0.0063 \\
\hline 37 & C & 350.0 & 24.10 & 0.90 & 0.0059 \\
\hline 38 & c & 742.0 & 4730 & 1.70 & 0.0059 \\
\hline 39 & C & 854.0 & 51.20 & 1.80 & 0.00352 \\
\hline 40 & C & 1540 & 20.30 & 0.70 & 0.0345 \\
\hline 41 & C & 268.0 & 2420 & 0.80 & 0.0331 \\
\hline 42 & C & 518.0 & 30.00 & 1.00 & 0.00383 \\
\hline 43 & C & 1276.0 & 76.70 & 2.30 & 0.00300 \\
\hline
\end{tabular}

«Surface Initially etched 
TABLE 4 - Welght Gains (mg/dm sq) of Alpha.Annealed Zrcaloy-4 Exposed in the Advanced Test Reactor

\begin{tabular}{|c|c|c|c|c|c|c|c|c|c|}
\hline \multirow[b]{2}{*}{ SPEC } & \multirow[b]{2}{*}{ INGOT } & \multirow[b]{2}{*}{ FuH } & \multirow[b]{2}{*}{ DAYS } & \multicolumn{2}{|c|}{$360^{\circ} \mathrm{C}(033.1 \mathrm{O}$} & \multirow[b]{2}{*}{ OWTGN } & \multirow[b]{2}{*}{ HWTGN } & \multirow[b]{2}{*}{$\mathrm{H} / \mathrm{O}$} & \multirow[b]{2}{*}{ AVTENP M } \\
\hline & & & & AVFLUX & FUENCE & & & & \\
\hline 1 & $\mathbf{B}$ & 11.18 & 71.7 & 0.530 & 3.3 & 50.4 & 1.1 & 0.0018 & $\infty 0.4$ \\
\hline 2 & $\mathbf{B}$ & 11.17 & 886.3 & 0.760 & 58.2 & 1010.6 & 21.4 & 0.0212 & $\infty 0.4$ \\
\hline 2 & B & 91.17 & 723.8 & 0.782 & 48. & 8143 & 170 & 0.0000 & $\infty$ \\
\hline 2 & B & 11.17 & 412.1 & 0.797 & 28.4 & 445.1 & 8.0 & 0.0002 & 028 \\
\hline 3 & $\mathbf{B}$ & 10.35 & 71.7 & 0.873 & 8.4 & 548 & 13 & 0.0237 & $\infty 00$ \\
\hline 4 & B & 10.78 & 886.2 & 1261 & $\$ 8.6$ & 1326.4 & 28.1 & 0.0197 & 0276 \\
\hline 5 & $\mathbf{B}$ & 11.18 & 4121 & 1.190 & 427 & 5472 & 128 & 0.0024 & 008 \\
\hline 5 & B & 11.18 & 558.6 & 1261 & 60.9 & $\pi$ T3.5 & 20.7 & 0.0006 & 020 \\
\hline 6 & $\mathbf{B}^{\circ}$ & 0.00 & 71.7 & 0.530 & $\mathbf{3 . 3}$ & 60.8 & 10 & 0.0167 & 6024 \\
\hline 7 & B & 0.00 & 71.7 & 0.873 & 8.4 & $\infty .7$ & 20 & 0,0314 & $\infty 00$ \\
\hline 8 & C & 11.00 & 4121 & 1.190 & 127 & 4020 & 162 & 0.0000 & $\infty$ \\
\hline $\boldsymbol{8}$ & C & 11.50 & 568.6 & 1281 & $\infty$ & 701.4 & 20,4 & 0.0034 & (2) \\
\hline - & c & 11.50 & 82 & 1281 & 86 & 12008 & 20.1 & $0.00 \times 2$ & 6028 \\
\hline 10 & $\mathbf{L}$ & 1.06 & 481.6 & 0.024 & 1.0 & 2026 & 10 & 0.0074 & $\infty$ \\
\hline 11 & C & 11.00 & 806.2 & 0.760 & 502 & $\$ 330$ & 213 & 0.0028 & $\infty 6$ \\
\hline 11 & C & 11.0 & 7238 & 0.782 & 480 & 7490 & 195 & 0,0200 & 200 \\
\hline 11 & C & 1100 & 412.1 & 0.797 & 23.4 & 4009 & 7.6 & 0.0185 & coses \\
\hline 12 & $\mathbf{L}$ & 124 & 481.5 & 1224 & 50.9 & $\cos 2$ & 11.1 & 0.0183 & 0227 \\
\hline 13 & D & 10.35 & 886.2 & 0.700 & 58.2 & 10086 & 20.1 & 0.0199 & 6205 \\
\hline 13 & D & 10.35 & 7238 & 0.782 & 489 & 814.7 & 170 & 0.0000 & 200 \\
\hline 13 & D & 10.35 & 412.1 & 0.797 & 28.4 & 460 & 9.3 & 0,00000 & 2025 \\
\hline 14 & D & 9.93 & 88622 & 1261 & 96.6 & 1318.3 & 20.1 & 0.0021 & 0276 \\
\hline 15 & D & 2.93 & 4121 & 1.190 & 427 & 5460 & 140 & 0.0056 & 6206 \\
\hline 15 & D & 9.03 & 658.6 & 1201 & $\infty$ & 770 & 21.1 & 0.0272 & 6200 \\
\hline 16 & L & 1408 & 611.8 & 1.360 & 73.4 & mece & 156 & 0.0000 & $\cos 4$ \\
\hline 17 & E & 1201 & 412.1 & 1.190 & 427 & 5008 & 128 & 0.0028 & $\infty 28$ \\
\hline 17 & $\boldsymbol{E}$ & 1201 & 558.6 & 1281 & $\infty 0$ & 754.7 & 100 & 0.00000 & 020 \\
\hline 18 & E & 10.78 & 8862 & 0.760 & 582 & 10008 & 21.7 & 0.0218 & 025 \\
\hline 18 & E & 10.70 & 723.8 & 0.782 & 48.9 & 8112 & 180 & 0.0002 & 200 \\
\hline 18 & E & 10.78 & 4121 & 0.797 & 28.4 & 41.7 & 9.7 & 0.0020 & $\cos 3$ \\
\hline 19 & E & 10.75 & 285.2 & 1261 & $\$ 6.6$ & 130000 & 20.1 & 0.0003 & 2278 \\
\hline 20 & F. & 11.50 & 71.7 & 0.530 & 3.3 & 480 & 1.4 & 0.0300 & 2024 \\
\hline 21 & F & 1242 & $\$ 12.1$ & 1.190 & 42.7 & 5430 & 13.2 & 0.0245 & 0206 \\
\hline 21 & $\boldsymbol{F}$ & 12.42 & 558.6 & 1261 & $\infty .8$ & $\pi 2$ & 168 & 0.0216 & 0200 \\
\hline 22 & $\boldsymbol{F}$ & 11.50 & 71.7 & 0.873 & 8.4 & 40.7 & 1.4 & 0.0262 & 0500 \\
\hline 23 & $\boldsymbol{F}$ & 11.00 & 88022 & 0.700 & 58.2 & 10026 & 200 & 0.0215 & $\infty 5$ \\
\hline 23 & $\mathbf{F}$ & 11.50 & 723.8 & 0.782 & 48.9 & 8000 & 19.0 & 0.00232 & $\infty$ \\
\hline
\end{tabular}

FuM = Oxido prefilm (mo/dm ea). Nogative values caued by meseurement error $F W X=(n / c m s q / \omega c) \times 10$ FUENCE $=(\mathrm{n} / \mathrm{cm} \times \mathbf{q}) \times 10$ 
TABLE \& (Cont'd) $\beta E 0^{\circ} \mathrm{C}$

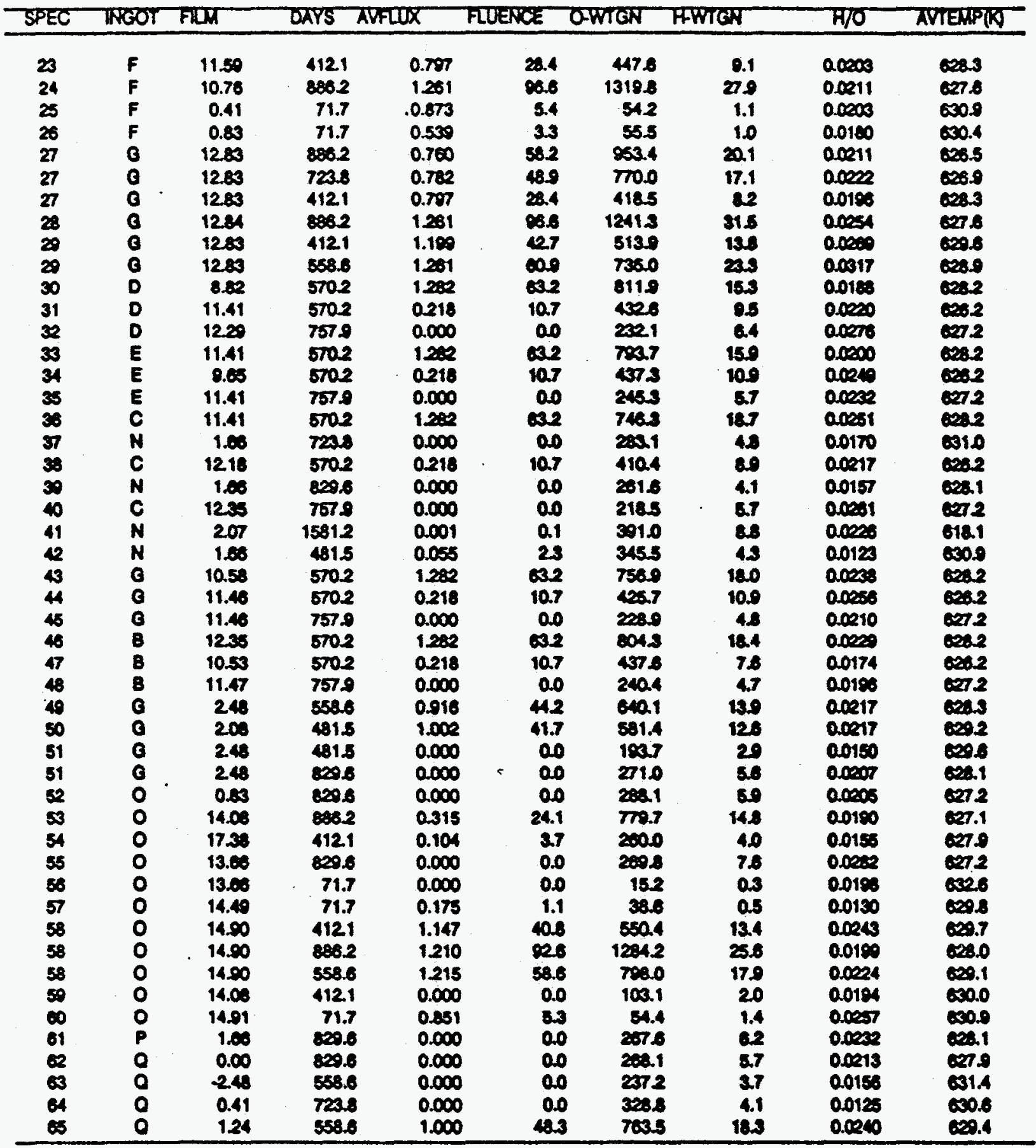


TABLE 4 (Cont'd) $\left(360^{\circ} \mathrm{C}\right)$

\begin{tabular}{|c|c|c|c|c|c|c|c|c|c|}
\hline SPEC & INGOI & ElWh & DAYS & AVFLUX & ELUENCE & QWIGN & H.WTGN & H20 & AVIEMPR \\
\hline $\begin{array}{l}66 \\
67 \\
68 \\
\frac{69}{70} \\
\frac{71}{11} \\
\frac{71}{72} \\
\frac{73}{74} \\
\frac{75}{76} \\
77 \\
78 \\
79 \\
\frac{80}{81} \\
\frac{82}{83} \\
83 \\
83 \\
\frac{84}{85} \\
86 \\
86 \\
87 \\
88\end{array}$ & 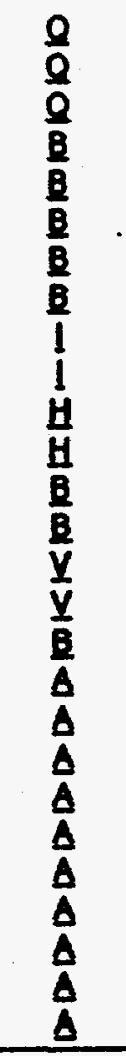 & $\begin{array}{c}\frac{0.83}{0.83} \\
\frac{2.07}{2.49} \\
\frac{2.06}{2.48} \\
\frac{2.48}{2.48} \\
\frac{2.48}{12.34} \\
\frac{11.84}{12.60} \\
\frac{11.73}{12.16} \\
\frac{13.20}{15.36} \\
\frac{11.71}{0.82} \\
\frac{10.65}{11.44} \\
\frac{11.44}{11.44} \\
\frac{11.46}{11.47} \\
\frac{9.55}{2.55} \\
\frac{0.41}{1.06}\end{array}$ & 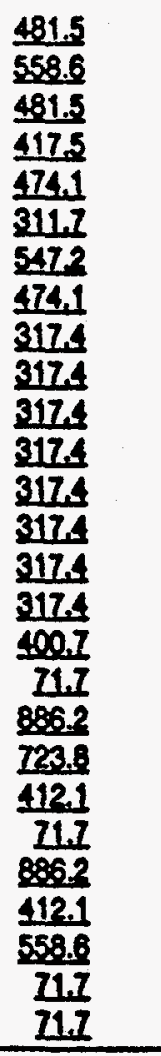 & $\begin{array}{l}\frac{0.837}{0.000} \\
0.000 \\
0.000 \\
\frac{1.110}{0.000} \\
\frac{0.000}{1.180} \\
0.163 \\
0.020 \\
0.163 \\
0.020 \\
0.163 \\
0.020 \\
0.020 \\
0.163 \\
\frac{0.001}{0.539} \\
0.760 \\
0.782 \\
0.797 \\
0.673 \\
\frac{1.261}{1.199} \\
\frac{1.261}{0.539} \\
0.873 \\
\end{array}$ & $\begin{array}{l}39.0 \\
0.0 \\
0.0 \\
0.0 \\
\frac{45.5}{0.0} \\
\frac{0.0}{48.3} \\
\frac{4.5}{0.5} \\
\frac{45}{0.5} \\
\frac{45}{0.5} \\
0.5 \\
\frac{45}{0.0} \\
\frac{3.3}{58.2} \\
\frac{48.9}{28.4} \\
\frac{5.4}{96.6} \\
\frac{42.7}{60.9} \\
\frac{3.3}{5.4} \\
\end{array}$ & 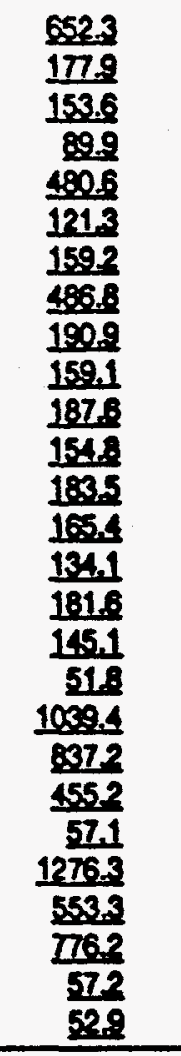 & $\begin{array}{l}\frac{12.0}{3.6} \\
\frac{3.4}{0.5} \\
\frac{8.9}{0.7} \\
\frac{1.9}{10.3} \\
\frac{4.8}{0.0} \\
\frac{5.8}{0.8} \\
\frac{1.5}{2.2} \\
\frac{1.8}{4.7} \\
\frac{12.2}{0.6} \\
\frac{14.6}{15.4} \\
\frac{7.7}{1.0} \\
\frac{24.1}{10.4} \\
\frac{15.5}{0.9} \\
\frac{0.7}{1} \\
\end{array}$ & $\begin{array}{l}0.0185 \\
0.0202 \\
0.0223 \\
0.0056 \\
0.0185 \\
0.0058 \\
0.0121 \\
0.0212 \\
0.0249 \\
0.0003 \\
0.00027 \\
0.0050 \\
0.0241 \\
0.0135 \\
0.0189 \\
0.0281 \\
0.0151 \\
0.0116 \\
0.0140 \\
0.0184 \\
0.0169 \\
0.0175 \\
0.0189 \\
0.0183 \\
0.0200 \\
0.0157 \\
0.0132 \\
\end{array}$ & 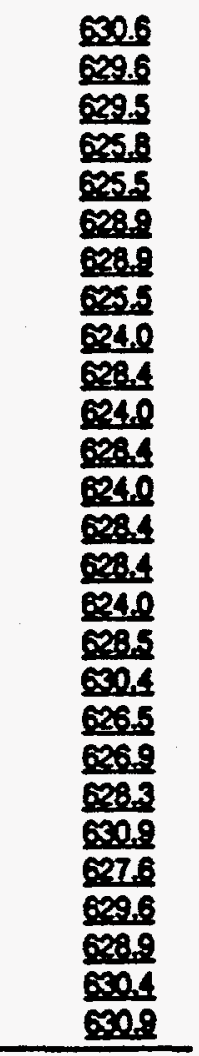 \\
\hline \multicolumn{10}{|c|}{$310^{\circ} \mathrm{C} 1530^{\circ} \mathrm{F}$} \\
\hline $\begin{array}{l}89 \\
90 \\
91 \\
92 \\
93 \\
94 \\
94 \\
95 \\
96 \\
96 \\
97 \\
98 \\
99 \\
100\end{array}$ & $\begin{array}{l}\mathbf{B} \\
\mathbf{B} \\
\mathbf{F} \\
U \\
\mathbf{D} \\
\mathbf{D} \\
\mathbf{D} \\
\mathbf{E} \\
\mathbf{E} \\
\mathbf{E} \\
\mathbf{C} \\
\mathbf{C} \\
\mathbf{C} \\
\mathbf{G}\end{array}$ & $\begin{array}{r}12.00 \\
10.25 \\
11.10 \\
16.17 \\
8.77 \\
11.41 \\
11.41 \\
-\quad 9.66 \\
10.44 \\
10.44 \\
11.41 \\
11.41 \\
11.41 \\
9.70\end{array}$ & $\begin{array}{c}1509.9 \\
997.5 \\
1210.3 \\
804.2 \\
997.5 \\
907.7 \\
1464.3 \\
907.5 \\
907.7 \\
1464.3 \\
997.5 \\
907.7 \\
1464.3 \\
897.5\end{array}$ & $\begin{array}{l}0.000 \\
1.471 \\
1.471 \\
1.469 \\
1.661 \\
0.594 \\
0.609 \\
1.661 \\
0.594 \\
0.609 \\
1.661 \\
0.594 \\
0.609 \\
1.661\end{array}$ & $\begin{array}{r}0.0 \\
126.7 \\
153.8 \\
103.5 \\
143.1 \\
46.6 \\
77.0 \\
143.1 \\
46.6 \\
77.0 \\
143.1 \\
46.6 \\
7.0 \\
143.1\end{array}$ & $\begin{array}{l}41.3 \\
208.2 \\
943.8 \\
163.3 \\
337.7 \\
213.5 \\
513.8 \\
326.5 \\
192.3 \\
480.8 \\
229.3 \\
153.8 \\
411.0 \\
509.8\end{array}$ & $\begin{array}{l}1.6 \\
7.2 \\
11.5 \\
1.9 \\
4.0 \\
4.7 \\
10.2 \\
5.5 \\
4.8 \\
10.5 \\
5.3 \\
1.9 \\
8.7 \\
5.9\end{array}$ & $\begin{array}{l}0.0378 \\
0.0346 \\
0.0122 \\
0.0116 \\
0.0118 \\
0.0220 \\
0.0180 \\
0.0168 \\
0.0239 \\
0.0218 \\
0.0231 \\
0.0124 \\
0.0212 \\
0.0116\end{array}$ & $\begin{array}{l}580.1 \\
584.4 \\
584.1 \\
582.1 \\
586.1 \\
588.4 \\
588.2 \\
586.1 \\
588.4 \\
588.2 \\
586.1 \\
588.4 \\
588.2 \\
586.1\end{array}$ \\
\hline
\end{tabular}


TABLE 4 (Cont'd) $\left(310^{\circ} \mathrm{C}\right)$

\begin{tabular}{|c|c|c|c|c|c|c|c|c|c|}
\hline SPEC & TMOT & Fाum & DAYS & AVFLUX & FLUENCE & OWTA & HWIGN & H7o & AVIEMP(K) \\
\hline 101 & G & 10.59 & 907.7 & 0.594 & 46.6 & 175.0 & 3.9 & 0.0223 & 588.4 \\
\hline 101 & $\mathbf{G}$ & 10.59 & 1464.3 & 0,600 & 77.0 & 568.9 & 6.6 & 0.0116 & 5882 \\
\hline 102 & $\mathbf{B}$ & 12.35 & 997.5 & 1.661 & 143.1 & 319.5 & 5.8 & 0.0182 & 586.1 \\
\hline 103 & B & 11.46 & $\mathbf{9 0 7 . 7}$ & 0.594 & 46.6 & 2172 & 5.0 & 0.0230 & 588.4 \\
\hline 103 & B & 11.46 & 1464.3 & 0.600 & $\pi 0$ & 502.8 & 8.8 & 0.0188 & 5882 \\
\hline 103 & B & 11.46 & 2107.8 & 0.623 & 113.4 & 861.1 & 19.5 & 0.0202 & 588.0 \\
\hline 104 & 1 & 11.70 & 838.2 & 1.697 & 122.8 & 98.3 & 3.6 & 0.0565 & 584.6 \\
\hline 104 & 1 & 11.70 & 909.8 & 1.713 & 148.0 & 283.0 & 4.4 & 0.0155 & 5842 \\
\hline 105 & 1 & 12.37 & 999.8 & 0.300 & 250 & 103.5 & 3.8 & 0.0368 & 580.1 \\
\hline 105 & 1 & 12.37 & 838.2 & 0.304 & 22.0 & 76.1 & 2.8 & 0.0568 & 580.7 \\
\hline 106 & H & 13.18 & 909.8 & 1.713 & 148.0 & 396.6 & 8.6 & 0.0218 & 5842 \\
\hline 107 & H & 12.91 & 999.8 & 0.300 & 25.8 & 106.0 & 3.7 & 0.0347 & 580.1 \\
\hline 107 & H & 12.91 & 838.2 & 0.304 & 220 & 75.4 & 2.4 & 0.0028 & 580.7 \\
\hline 108 & $J$ & 12.81 & 299.8 & 1.713 & 148.0 & 470.2 & 5.7 & 0.0122 & 5842 \\
\hline 109 & $J$ & 14.49 & 9998 & 0.300 & 258 & 95.3 & 42 & 0.0415 & 580.1 \\
\hline 100 & $J$ & 14.49 & 838.2 & 0.304 & 220 & 68.4 & 2.1 & 0.0004 & 580.7 \\
\hline 110 & B & 11.73 & 8382 & 1.697 & 1228 & 108.6 & 32 & 0.00022 & 5848 \\
\hline 110 & B & 11.73 & 92.8 & 1.713 & 148.0 & 237.4 & 5.9 & 0.0240 & 5842 \\
\hline 111 & v & 13.96 & 838.2 & 1.697 & 1228 & 162.8 & 3.5 & 0.0216 & 584.7 \\
\hline 111 & v & 13.96 & 999.8 & 1.713 & 148.0 & 480.2 & 8.3 & 0.0173 & 5842 \\
\hline 112 & v & 15.01 & 999.8 & 0.300 & 259 & 116.3 & 3.3 & 0.0281 & 580.1 \\
\hline 112 & $v$ & 15.01 & 838.2 & 0.304 & 22.0 & 84.5 & 4.6 & 0.0539 & 580.7 \\
\hline 113 & 8 & 2.05 & 1406.5 & 1.388 & 168.7 & 744.7 & 14.7 & 0.0188 & 5862 \\
\hline 114 & $\mathbf{s}$ & 13.67 & 8042 & 1.489 & 103.5 & 113.0 & 1.5 & 0.0130 & 582.1 \\
\hline 115 & $w$ & 10.00 & 543.3 & 0.000 & 0.0 & 124 & 0.1 & 0.0121 & 588.4 \\
\hline 116 & $w$ & 10.80 & 543.3 & 1.355 & $\varpi 3.6$ & 57.4 & 1.1 & 0.0193 & 588.7 \\
\hline 117 & $\mathbf{W}$ & 10.40 & 155.3 & 1.340 & 180 & 13.0 & 0.7 & 0.0522 & 586.7 \\
\hline 118 & $w$ & 10.80 & 155.3 & 1.340 & 18.0 & 139 & 02 & 0.0151 & 586.7 \\
\hline 118 & $w$ & 10.00 & 387.9 & 1.340 & 49 & 28.1 & 0.6 & 0.0208 & 5882 \\
\hline 120 & B & 8.90 & 538.0 & 0.528 & 245 & 372 & 0.8 & 0.0212 & 584.4 \\
\hline 121 & B & 8.92 & 1745.4 & 1.196 & 180.4 & 1051.5 & 16.4 & 0.0156 & 587.3 \\
\hline 121 & B & 9.92 & 2048.0 & 1.198 & 212.0 & 1421.6 & 20.0 & 0.0141 & 5872 \\
\hline 122 & B & 9.80 & 538.0 & 1.271 & 59.1 & 32.7 & 0.5 & 0.0153 & 587.2 \\
\hline 123 & A & 1.46 & 2045.7 & 0.465 & 822 & 722.2 & 8.6 & 0.0132 & 5882 \\
\hline 124 & A & 9.75 & 1297.3 & 1.537 & 172.3 & 3042 & 5.4 & 0.0137 & 5848 \\
\hline 124 & A & 9.75 & 2045.7 & 1.585 & 280.1 & 1215.5 & 17.0 & 0.0140 & 5846 \\
\hline 125 & A & 9.75 & 1297.3 & 0.437 & 49.0 & 336.2 & 5.6 & 0.0167 & 588.3 \\
\hline 125 & A & 9.75 & 2045.7 & 0.465 & 822 & 727.1 & 11.1 & 0.0152 & 588.2 \\
\hline 126 & $F$ & 10.57 & 1297.3 & 0.437 & 49.0 & 351.1 & 11.3 & 0.0022 & 588.3 \\
\hline 126 & $\boldsymbol{F}$ & 10.57 & 2045.7 & 0.465 & 82.2 & 848.5 & 24.6 & 0.0200 & 588.2 \\
\hline 127 & $\boldsymbol{F}$ & 9.76 & 12973 & 1.537 & 172.3 & 923.0 & 15.6 & 0.0169 & 5849 \\
\hline 127 & $F$ & 9.76 & 2045.7 & 1.585 & 280.1 & 2279.8 & 30.8 & 0.0136 & 584.6 \\
\hline 128 & $\boldsymbol{F}$ & 0.98 & 2045.7 & 0.465 & 82.2 & 8113 & 21.5 & 0.0265 & 568.2 \\
\hline 129 & B & 0.65 & 1297.3 & 1.537 & 1723 & 605.4 & 9.3 & 0.0140 & 5849 \\
\hline 130 & 8 & 0.74 & 1297.3 & 0.437 & 49.0 & 352.8 & 5.4 & 0.0153 & 388.3 \\
\hline 130 & B & 0.74 & 2045.7 & 0.465 & 822 & 776.7 & 14.0 & 0.0180 & 5882 \\
\hline 131 & D & 8.94 & 1297.3 & 1.537 & 172.3 & \$1.7 & 129 & 0.0204 & 5848 \\
\hline 131 & D & 8.94 & 2045.7 & 1.565 & 200.1 & 1927.3 & 24.7 & 0.0128 & 584.6 \\
\hline 132 & D & 8.94 & 1297.3 & 0.437 & 49.0 & 337.1 & 7.1 & 0.0211 & 588.3 \\
\hline
\end{tabular}


TABLE 4 (Cont'd) $\left(310^{\circ} \mathrm{C}\right)$

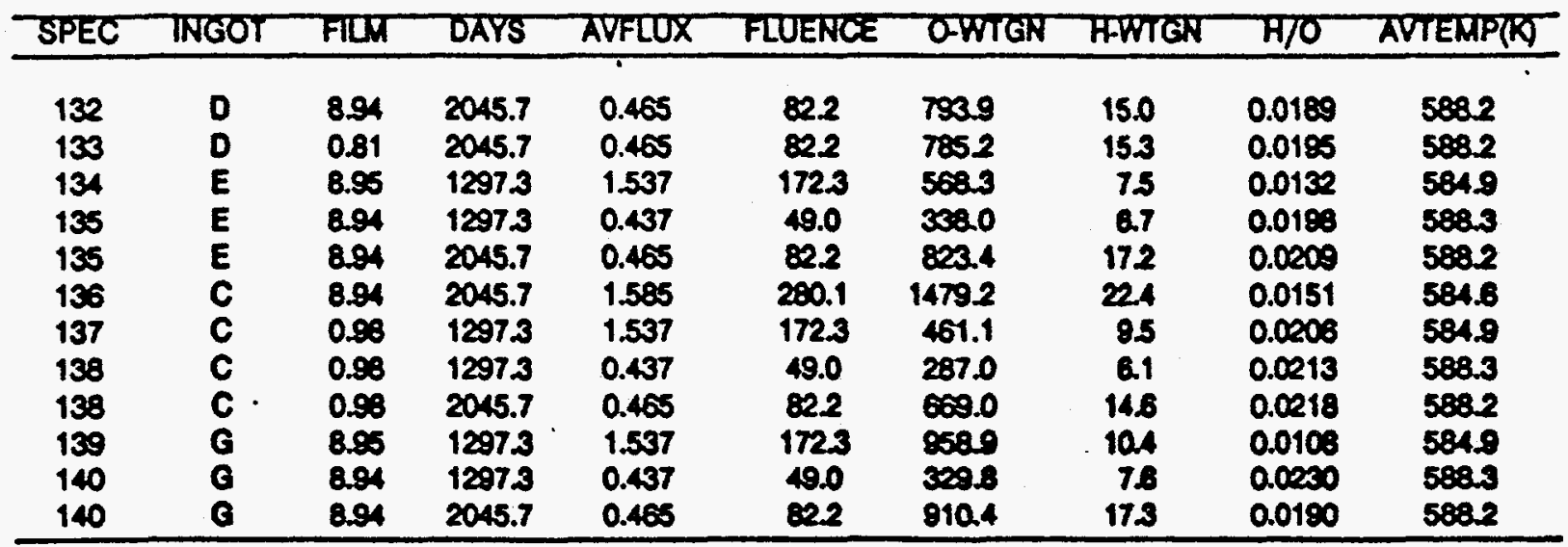


TABLE 5 - Chemistry of the Zircaloy-4" Exposed in the Advanced Test Reactor (ppm by weight)

\begin{tabular}{|c|c|c|c|c|c|c|c|c|c|c|c|c|c|c|c|}
\hline Mcot & Mat & SN & FE & 0 & $O R$ & 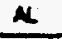 & C & $\boldsymbol{\alpha}$ & $H F$ & N & $N$ & NB & 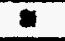 & $\mathbf{I A}$ & $\mathbf{a}$ \\
\hline$A$ & 2 & 14000 & 1500 & 700 & $\infty$ & 3 & 101 & $<\infty$ & $<120$ & $<2$ & 18 & $<100$ & 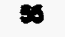 & $<200$ & $s$ \\
\hline e & 2 & 14000 & 2100 & 1400 & 100 & $<x$ & $<13$ & $<0$ & $\boldsymbol{*}$ & 28 & $<5$ & eCo & $\alpha \infty$ & $<100$ & $\infty$ \\
\hline c & 2 & 12000 & 2000 & 100 & 1100 & $<3$ & $<13$ & $<8$ & $<\theta$ & $<28$ & 43 & $<80$ & $<\infty$ & $<100$ & $\Leftrightarrow$ \\
\hline D & 2 & 14000 & 1000 & 100 & 1000 & $<$ & C1:s & 2 & $m$ & $<2$ & $<4$ & $<0$ & $<\infty$ & $<100$ & \\
\hline$E$ & 2 & 1400 & 2000 & 1500 & 100 & $<$ & ets & $x$ & $\omega$ & $<8$ & $<0$ & $c e$ & $<0$ & ews & \\
\hline$F$ & 2 & 19700 & 2100 & $1=3$ & 1000 & $\infty$ & 10 & $<\omega$ & 7 & $<10$ & - & $<100$ & $<$ & sed & \\
\hline e & 2 & 14000 & 2000 & $\infty$ & 1000 & $<8$ & $\bullet$ & $\mathbf{M}$ & 5 & $<2$ & $<28$ & - & $\infty$ & - & \\
\hline $\mathbf{H}$ & 2 & 10000 & 2400 & 1000 & 100 & 4 & 14 & $\boldsymbol{x}$ & $x$ & $<23$ & $<25$ & $<90$ & 74 & $<100$ & $\alpha$ \\
\hline 1 & 3 & 16100 & 2100 & 100 & $\boldsymbol{1 0 0}$ & $\infty$ & $<100$ & $\theta$ & $\mathbf{4}$ & $<8$ & cas & $<\infty$ & 7 & $<100$ & \\
\hline$J$ & 2 & $14 \times 0$ & 2100 & 1200 & 1000 & $\infty$ & $<10$ & 2 & $<$ & $<23$ & <e & $<\infty$ & $n$ & $<100$ & \\
\hline$L$ & 2 & 18000 & 2100 & 100 & 100 & 4 & 10 & 4 & $\infty$ & 4 & $\leftrightarrow$ & ets & 0 & cist & \\
\hline 4 & 2 & $18 \times 00$ & nes & $1+\infty$ & $\infty 00$ & $a$ & 100 & 2 & $e 0$ & 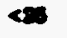 & 4 & $<0$ & $a$ & $<100$ & \\
\hline$n$ & 2 & 16000 & 2100 & 140 & $\infty \infty$ & 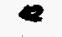 & 16 & $\infty$ & $<$ & $<$ & $<$ & $<4$ & $\infty$ & $<100$ & \\
\hline 0 & 2 & 1000 & 2100 & 100 & 110 & $\oplus$ & 19 & $\infty$ & 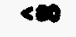 & 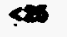 & $<$ & 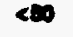 & $n$ & $<100$ & \\
\hline$P$ & 2 & 18000 & 2100 & 1400 & 1100 & $\infty$ & 19 & $<20$ & 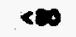 & $<2$ & ess & $<0$ & $a$ & $<100$ & \\
\hline $\mathbf{0}$ & 2 & 18500 & 2100 & 100 & 1100 & $a$ & 120 & $<2$ & $<10$ & $<2$ & $<3$ & $<8$ & $\nabla$ & $<100$ & $\infty$ \\
\hline ค & 3 & 1000 & 1810 & 1400 & 100 & $\mathbf{c}$ & $\boldsymbol{\infty}$ & $x$ & $\varnothing$ & 7 & 8 & $\infty$ & 1 & 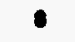 & $*$ \\
\hline 9 & 3 & 10000 & 1810 & 10 & 1100 & C. & $\boldsymbol{\omega}$ & $x$ & 8 & 7 & 8 & 0 & 4 & $\bullet$ & $\theta$ \\
\hline $\mathbf{T}$ & 3 & $18 \times 0$ & $20 x$ & 140 & 1100 & 4 & 10 & 10 & 41 & - & 2 & 1 & 10 & $\mathbf{t}$ & 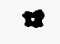 \\
\hline $\mathbf{v}$ & 3 & 18000 & 2000 & 100 & 1100 & 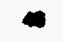 & 10 & $\boldsymbol{\omega}$ & 4 & 1 & 2 & $\boldsymbol{1}$ & 180 & $\mathbf{s}$ & 1 \\
\hline$v$ & 3 & 14400 & 2000 & 1300 & $\sec$ & 0 & $<100$ & $<2$ & $<0$ & $<20$ & 23 & $<\infty$ & $\omega$ & $<100$ & $\infty$ \\
\hline$w$ & s. & 18100 & 2100 & 1204 & $\infty$ & 23 & 123 & 10 & 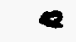 & $<10$ & 17 & - & $a$ & $<100$ & $\infty$ \\
\hline
\end{tabular}

*The "A" parameter $A=\Sigma t_{1}$ loop $(-79480 / R T)$ where $t$ and $T_{1}$ are post beta quench anneal times and temperatures for the alpha annealed coupons produced from these Ingots is $A=2.7 \times 10^{-16}$. 
I. INERT GAS FUSION OF CORROSION COUPON SECTIONS

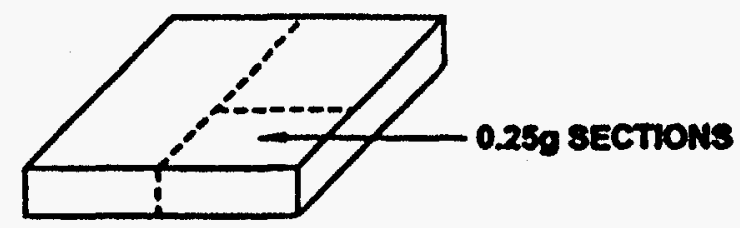

11. NEUTRON BEAM ATTENUATION
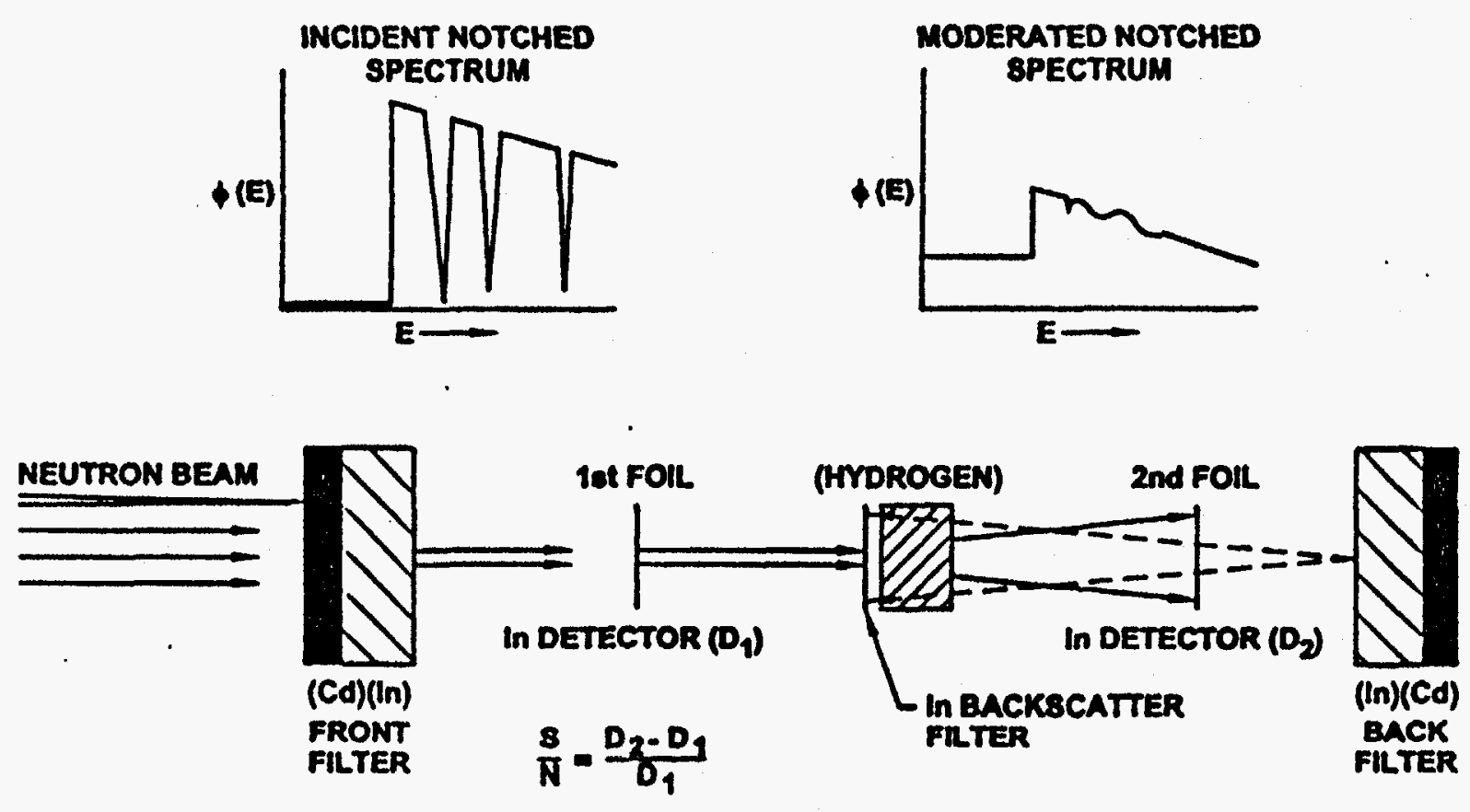
EXPERMENTAL ARR NGEMENT FOR NOTCHED
BPECTRUM MEASUREMENTS

Figure 1 Methods Use to Measure the Hydrogen Pickup 


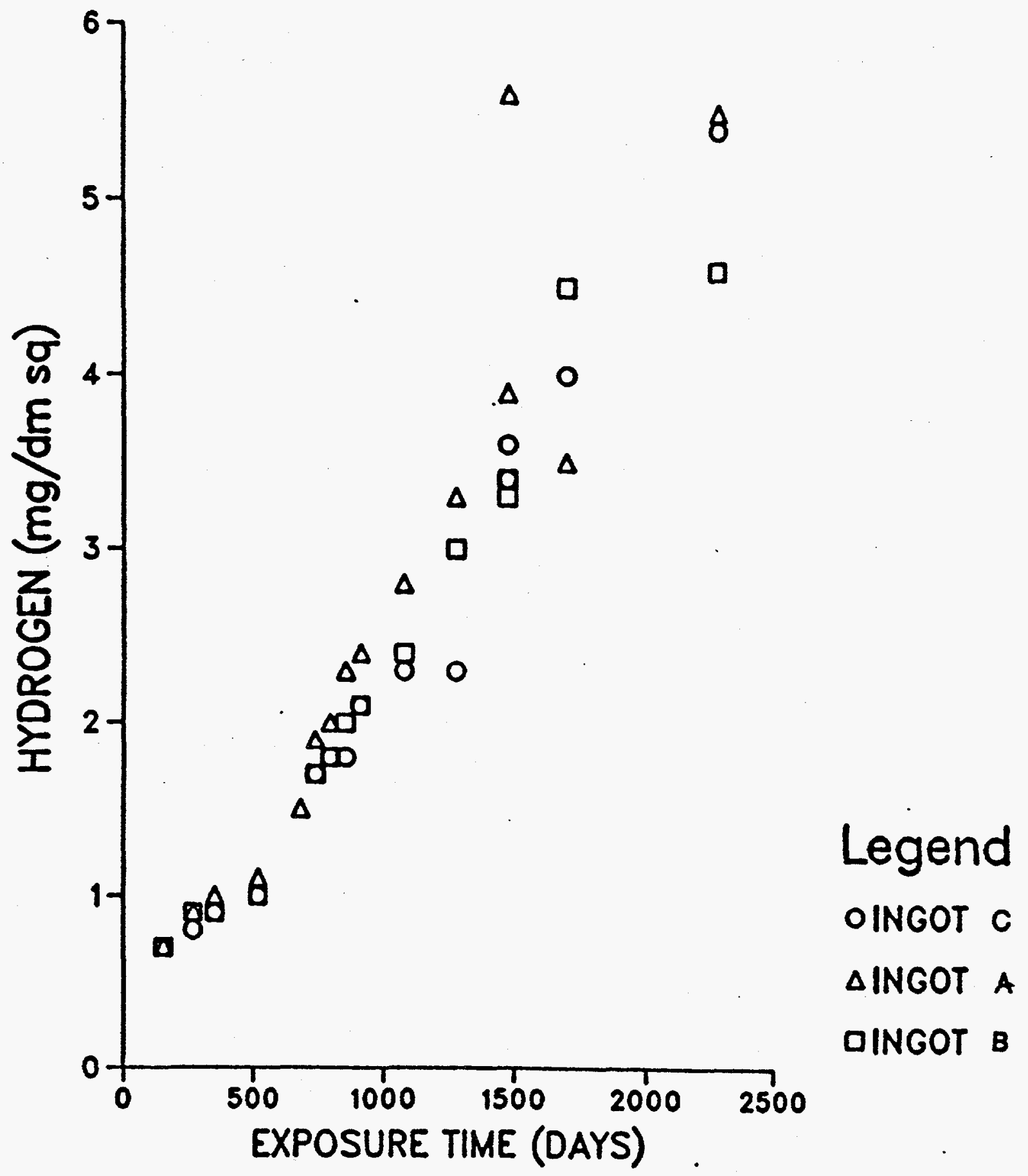

Figure 2 Hydrogen Pickup of Alpha-Annealed Zircaloy-4 Exposed in Autoclave at $316^{\circ} \mathrm{C}$ 


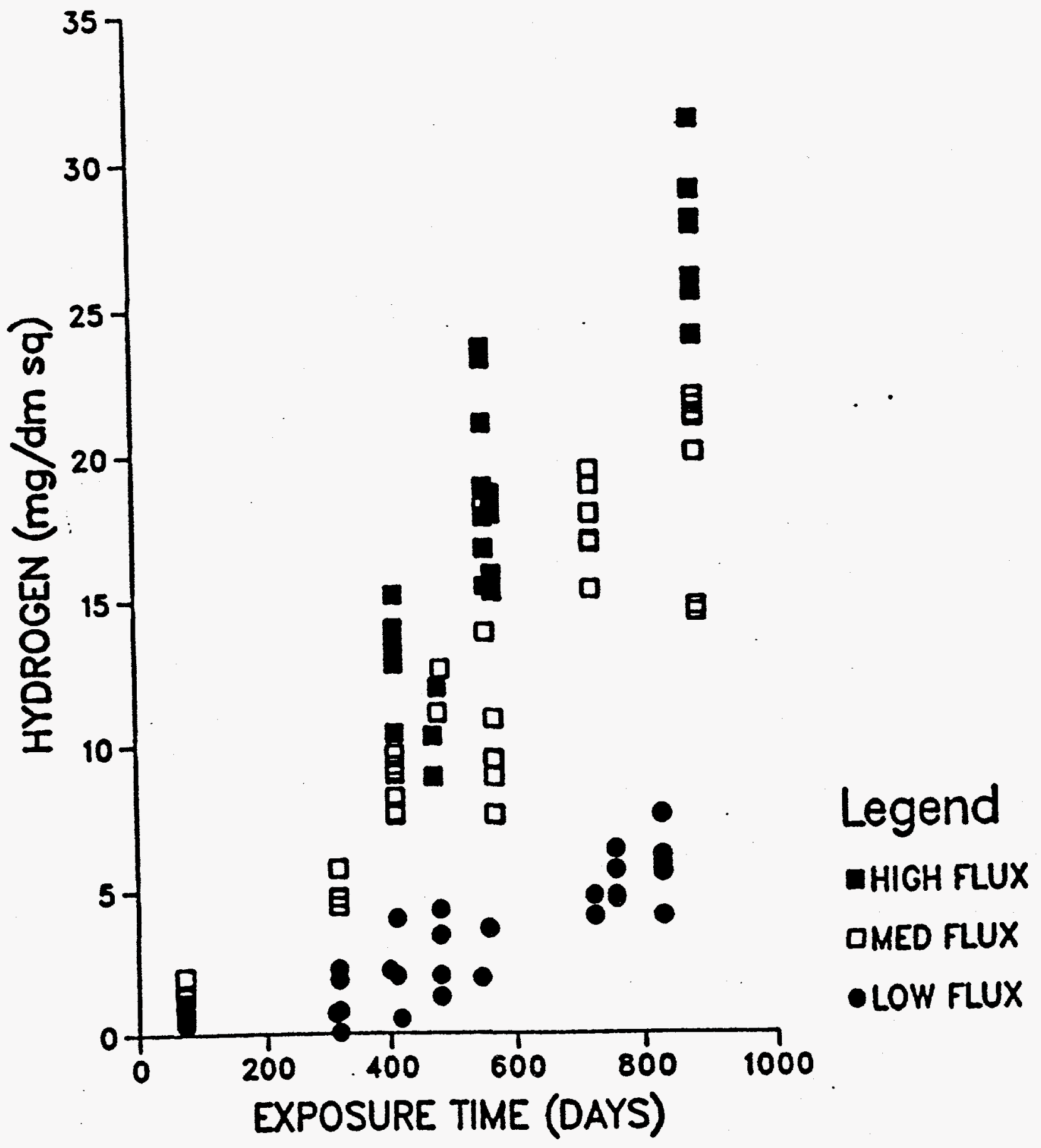

Figure 3 Hydrogen Pickup of Alpha-Annealed Zrcaloy-4 Exposed in the ATR at $360^{\circ} \mathrm{C}$ 


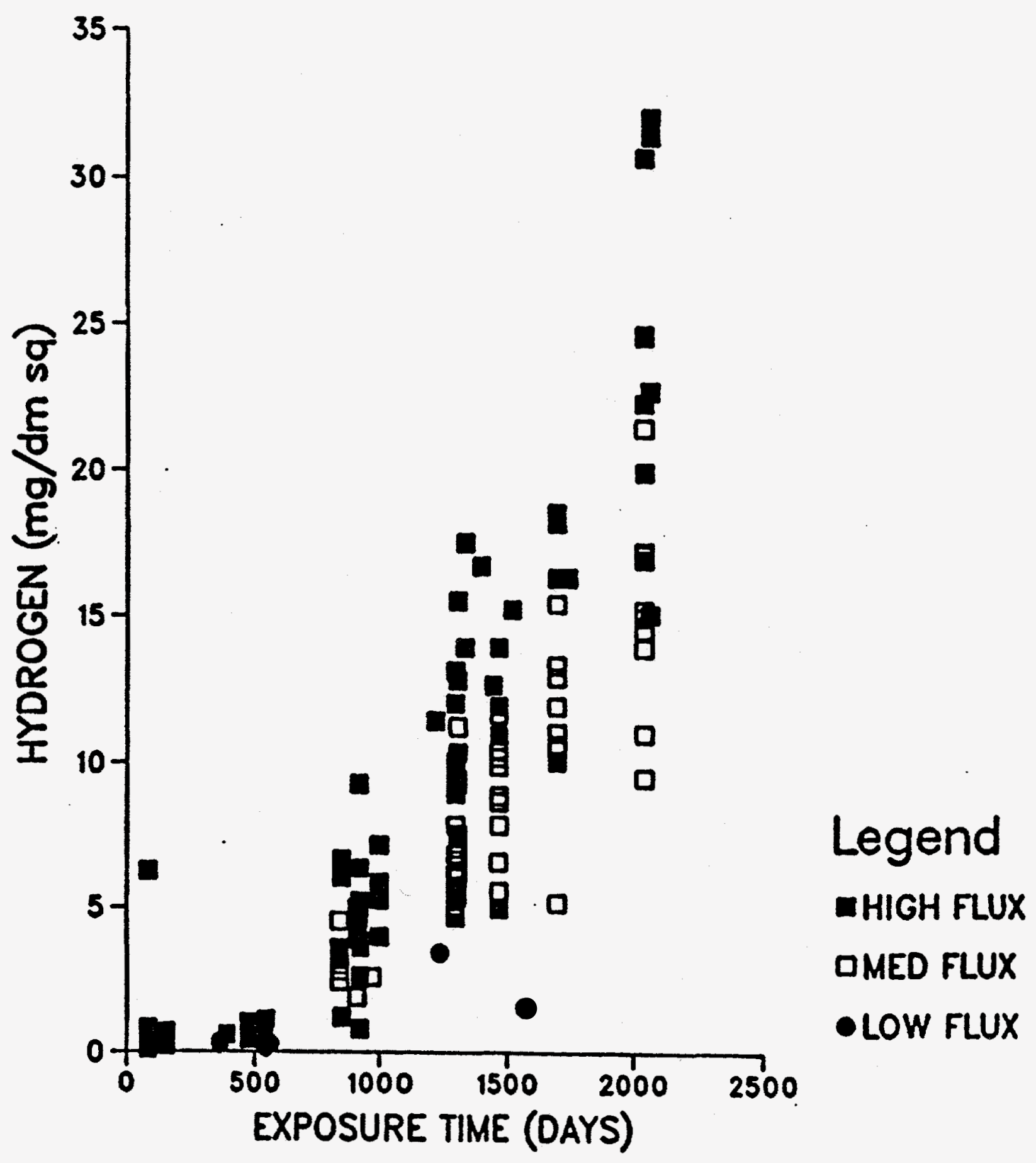

Figure 4 Hydrogen Pickup of Alpha-Annealed Zrcaloy-4 Exposed in the ATR at $310^{\circ} \mathrm{C}$ 


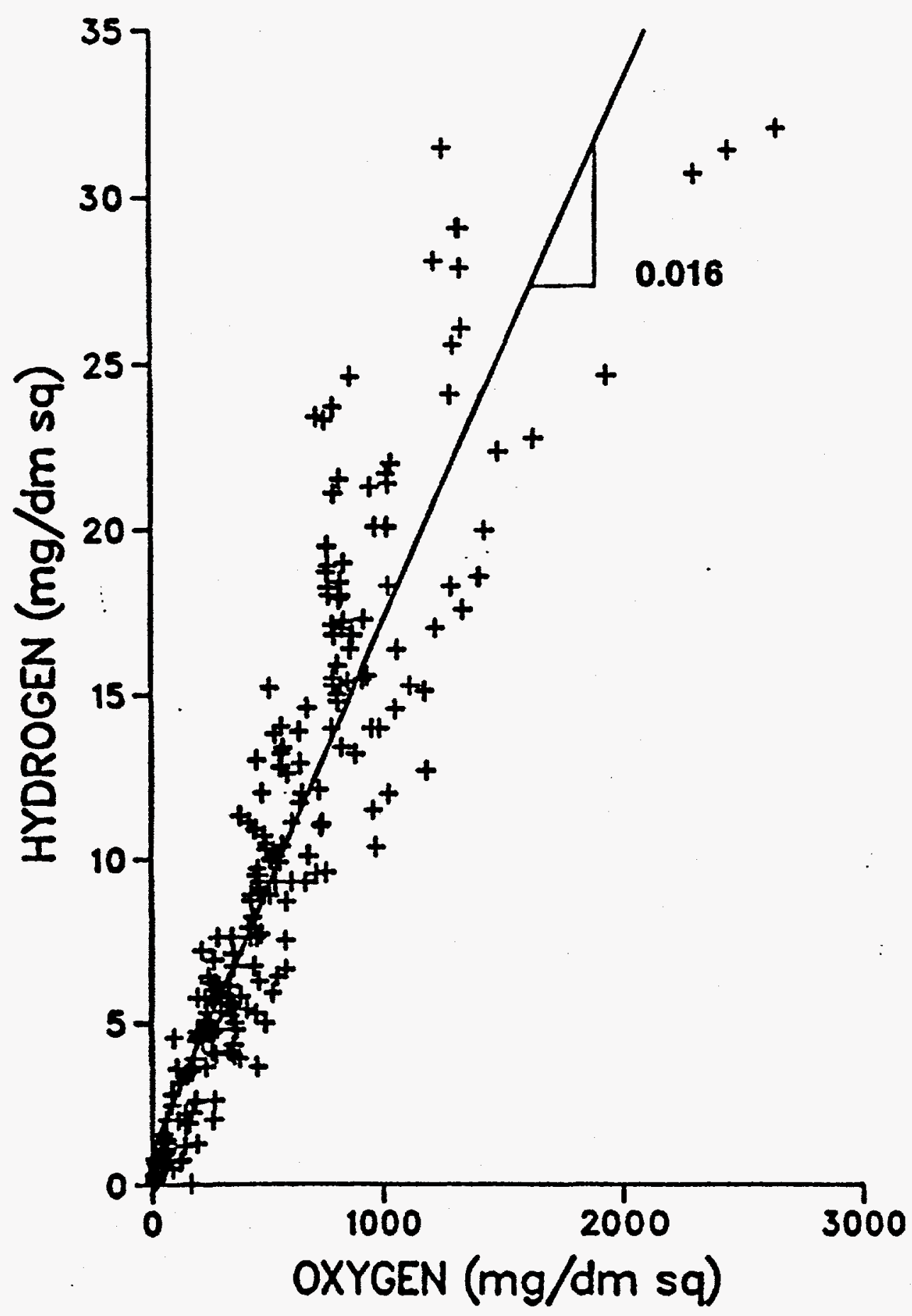

Flgure 5 Hydrogen Pickup of Alpha-Annealed Zrcaloy-4 Exposed in the ATR at 310 and $360^{\circ} \mathrm{C}$ Versus Oxygen Weight Gain 


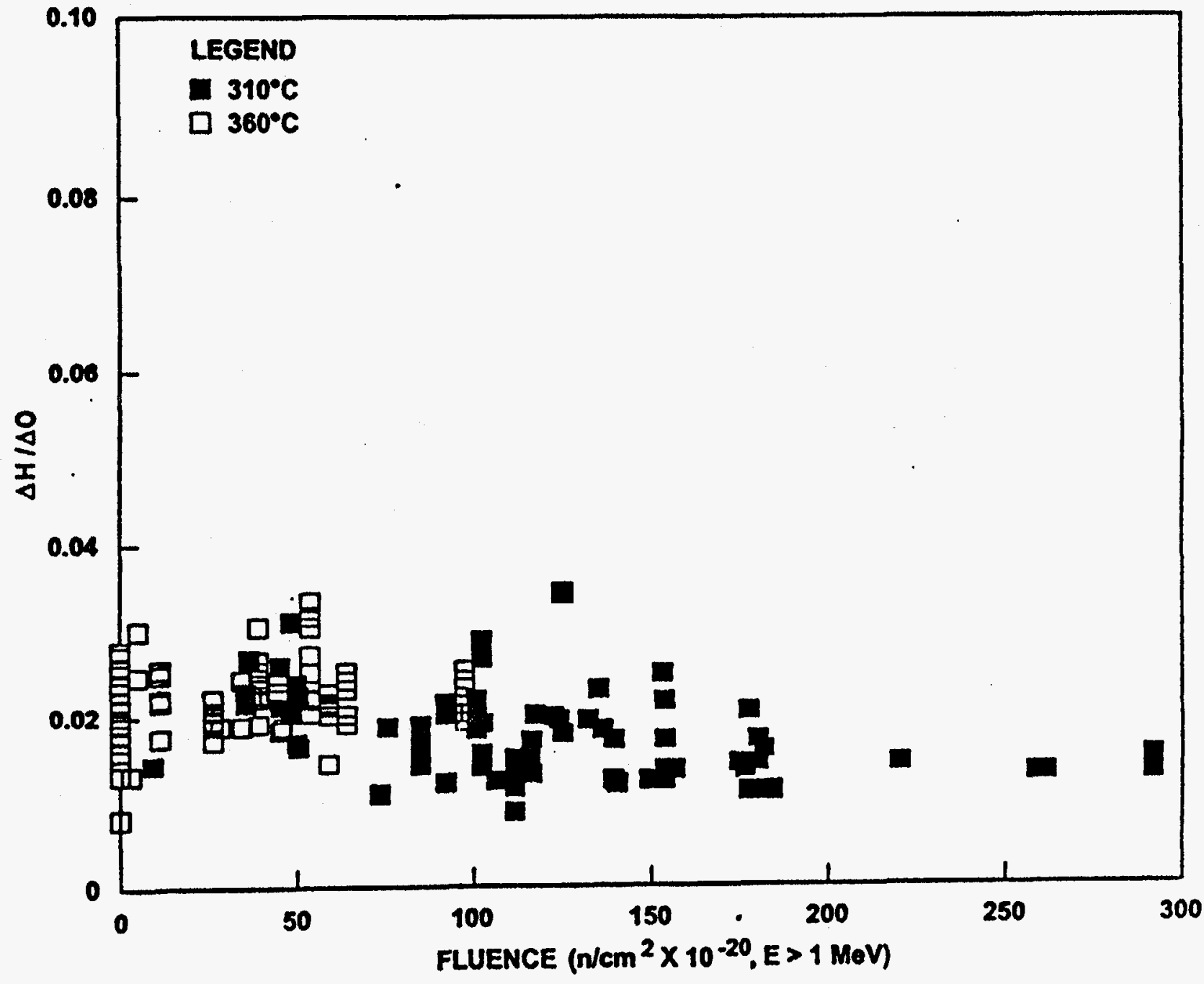

Figure 6 Hydrogen-to-Oxygen Weight Gain Ratio of Alpha-Annealed Zircaloy-4 Exposed in the ATR Versus Fluence 
$360^{\circ} \mathrm{C}$ WATER FILM

FILM THICKNESS $25 \mu \mathrm{m}$

TRANSVERSE SECTION OF SPECIMEN AS SEEN IN A $150 \mu \mathrm{m}$ FIELD SIMS IMAGE
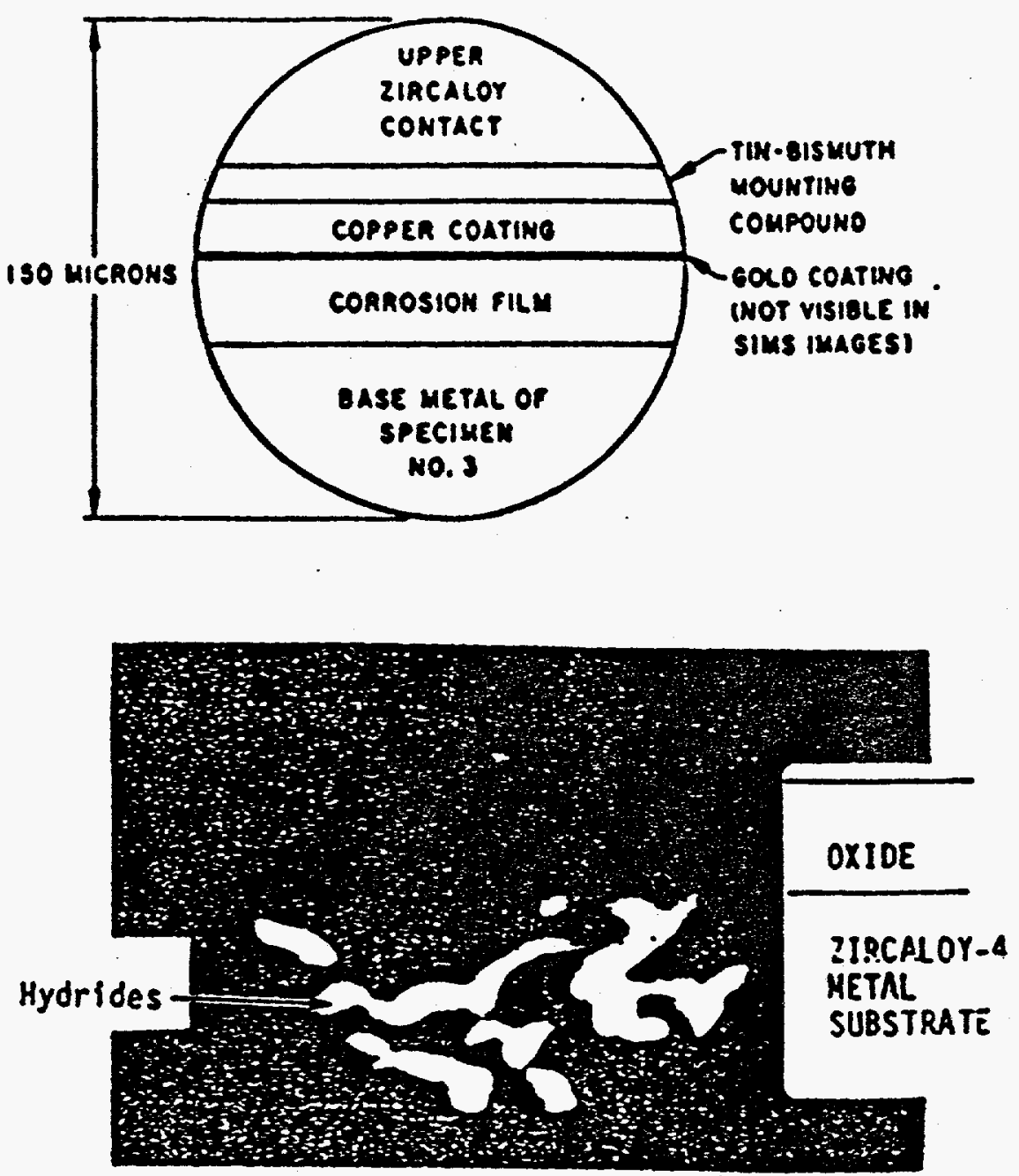

$1_{H}$ SIMS IMAGE OF A SECOND PORTION OF SPECIMEN 33. CE PRIMARY BEAM, 150 MICRON FIELD, 60 SECOND DATA COLLECTION.

Figure 7 Hydrogen Distribution in the Oxde Film and Metal Substrate 


\section{INERT GAS FUSION ${ }^{\dagger}$ OF SAMPLES WITH AND WITHOUT OXIDE FILMS}

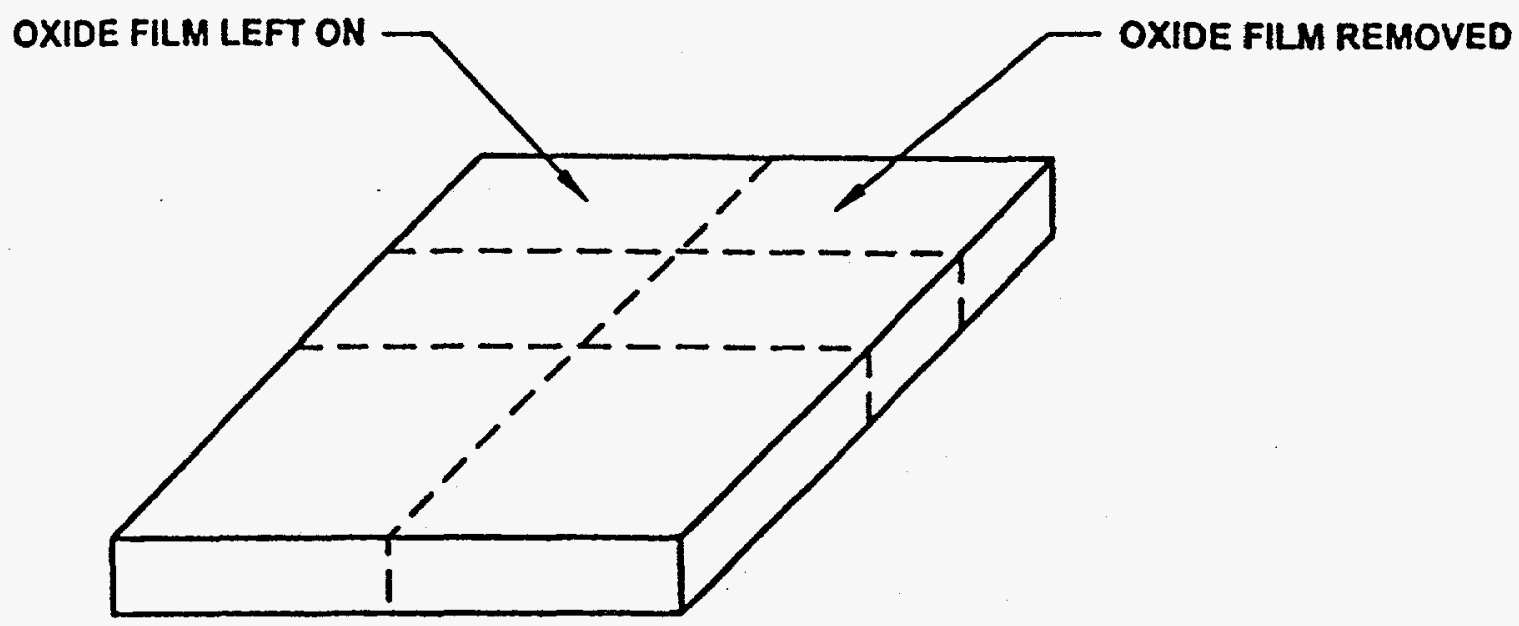

CONCENTRATION OF OXIDE FILM FOUND AS FOLLOWS

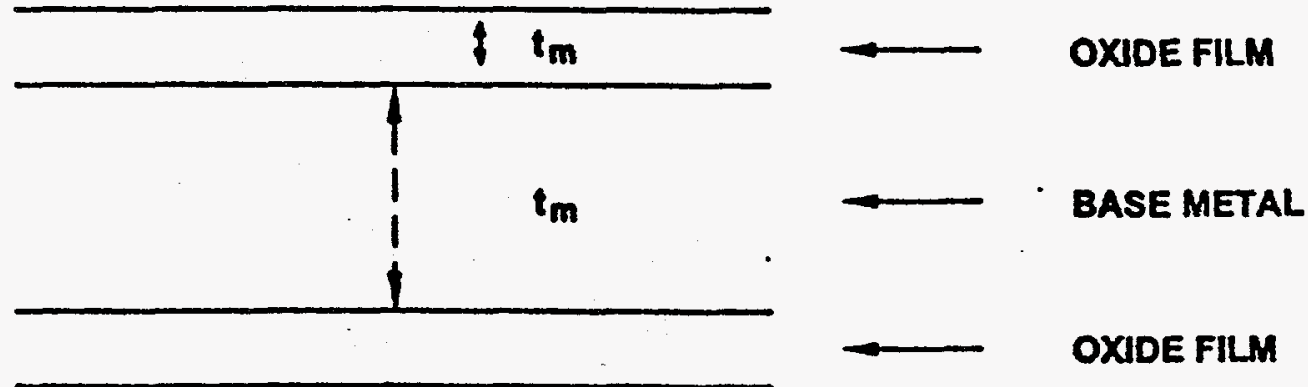

$$
C_{T}\left(t_{m} \rho_{m}+2 t_{0} \rho_{0}\right)=C_{m} t_{m} \rho_{m}+2 C_{o \rho_{o} t_{0}}
$$

WHERE $C_{T}$-IS THE TOTAL HYDROGEN CONCENTRATION OF THE SAMPLE MEASURED WITH THE OXIDE FILM LEFT ON (PPM BY WEIGHT)

$c_{m}$-IS THE HYDROGEN CONCENTRATION OF THE METAL (PPM BY WEIGHT)

$c_{0}$-IS THE HYDROGEN CONCENTRATION OF THE OXIDE (PPM BY WEIGHT)

$i_{m}$-IS THE BASE METAL THICKNESS (CM)

$t_{0}$ - IS THE OXIDE FILM THICKNESS (CM)

$P_{m}-1 S$ THE DENSITY OF ZIRCALOY $\left(6.545 \mathrm{G}^{-\mathrm{CM}^{3}}\right)$

$P_{0}$ - IS THE DENSITY OF THE OXIDE FILM (5.65 $\left.\mathrm{G} / \mathrm{CM}^{3}\right)$

+ SAMPLE MELTED AND YOLUME OF HYDROGEN RELASED DETERMINED.

Figure 8 Method Used to Determine Hydrogen in the Oxide Film 


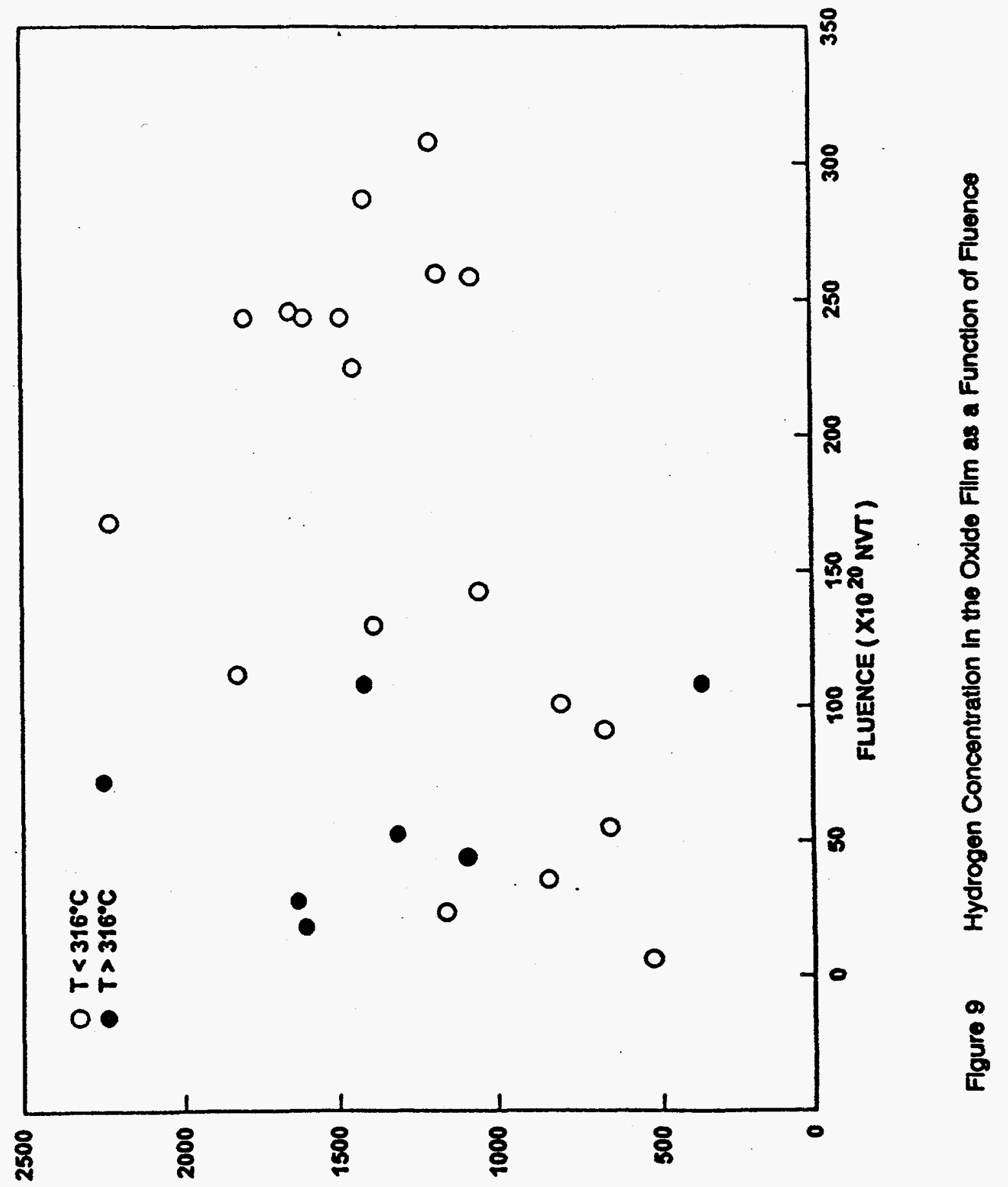

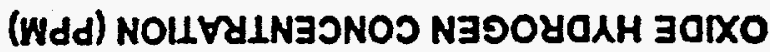




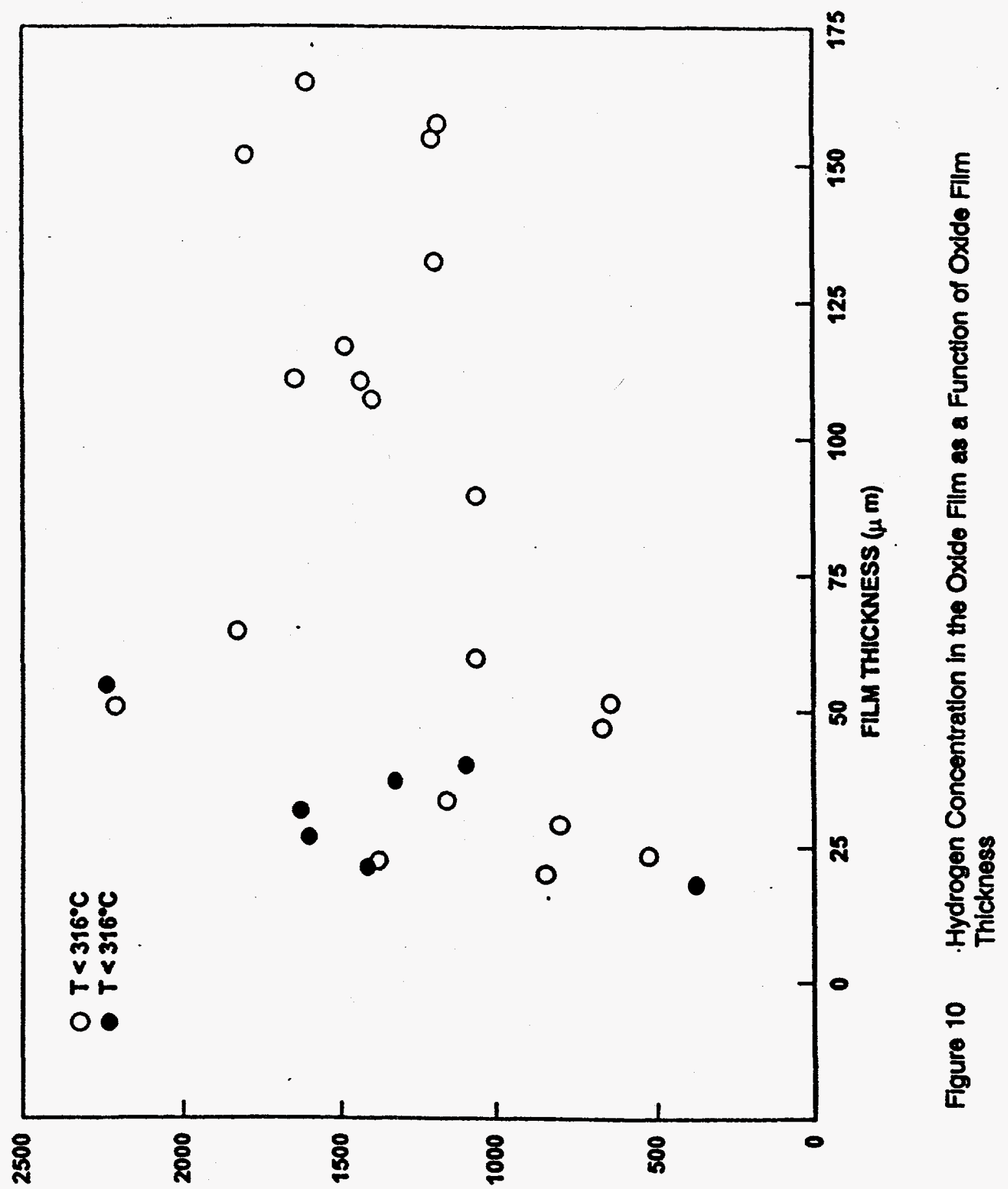

(Ndd) NOLYZINJONOJ NGOOYOLH JOXXO 

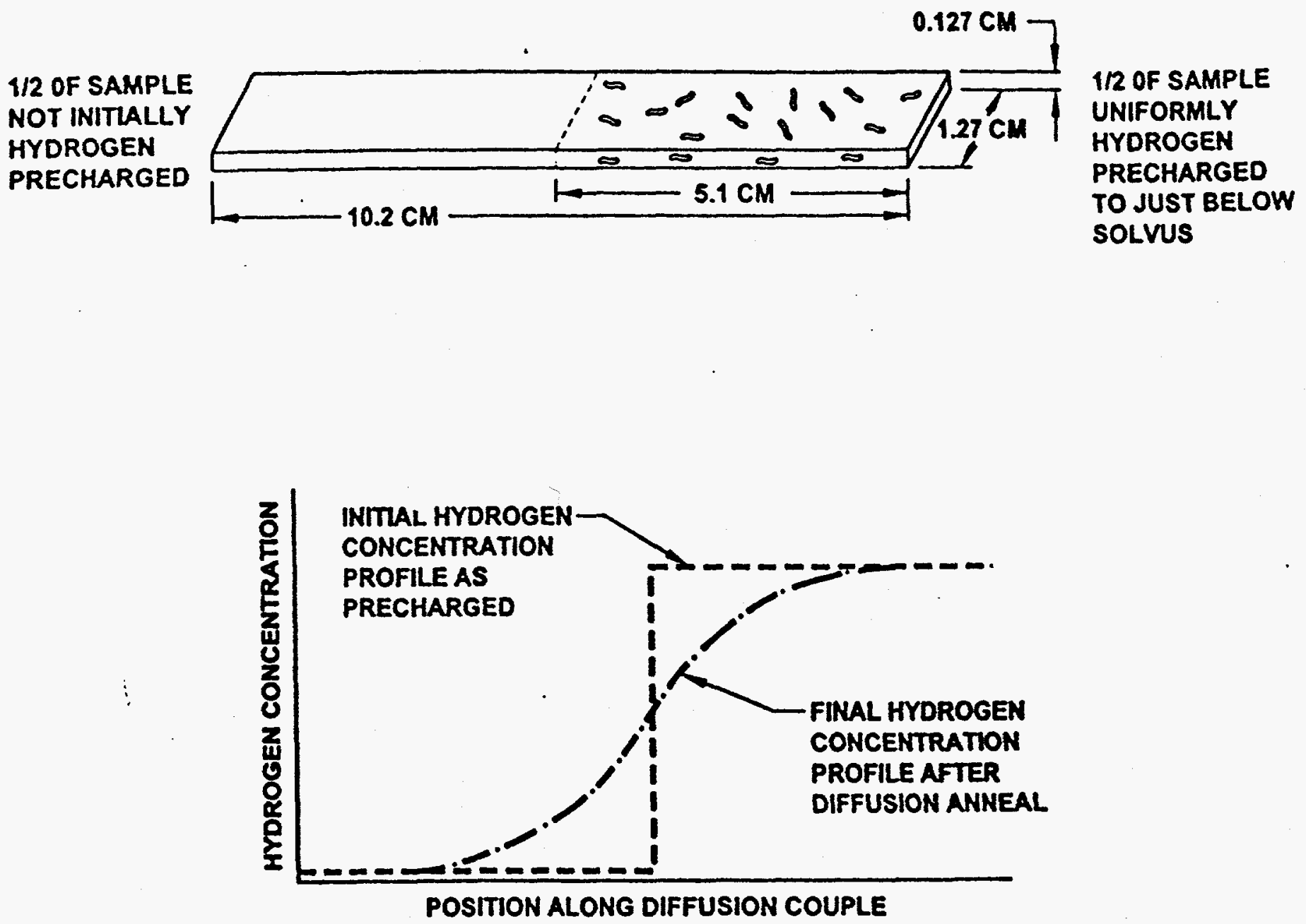

Figure 11 Preparation and Testing Sequence of Samples to Determine the HydrogenDiffusion Knetics and Hydrogen Solvus 


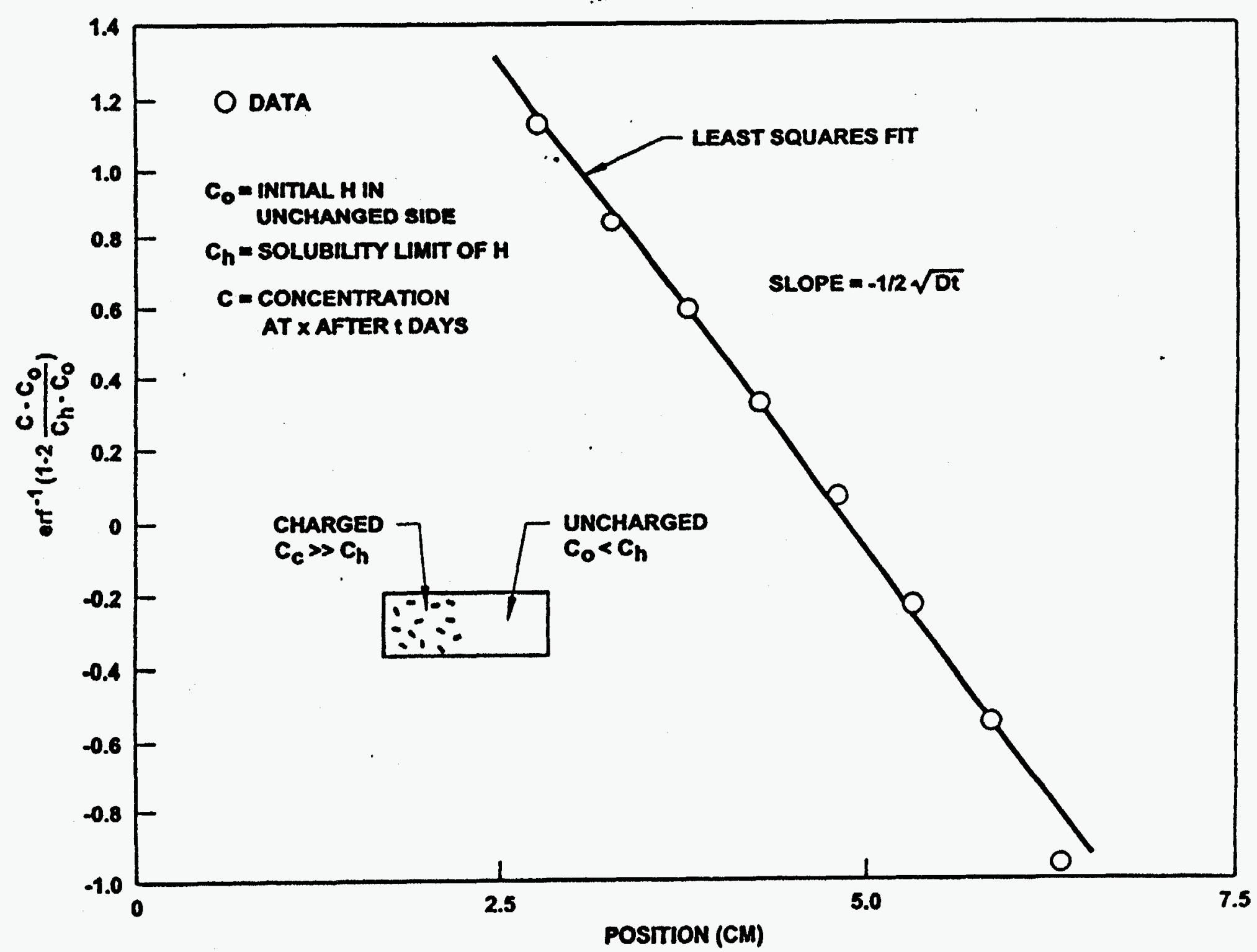

Flgure 12 Alpha-Annealed Zircaloy-4 Dithusion Couple Results Atter Exposure of 3.9 Days at $427^{\circ} \mathrm{C}$ 


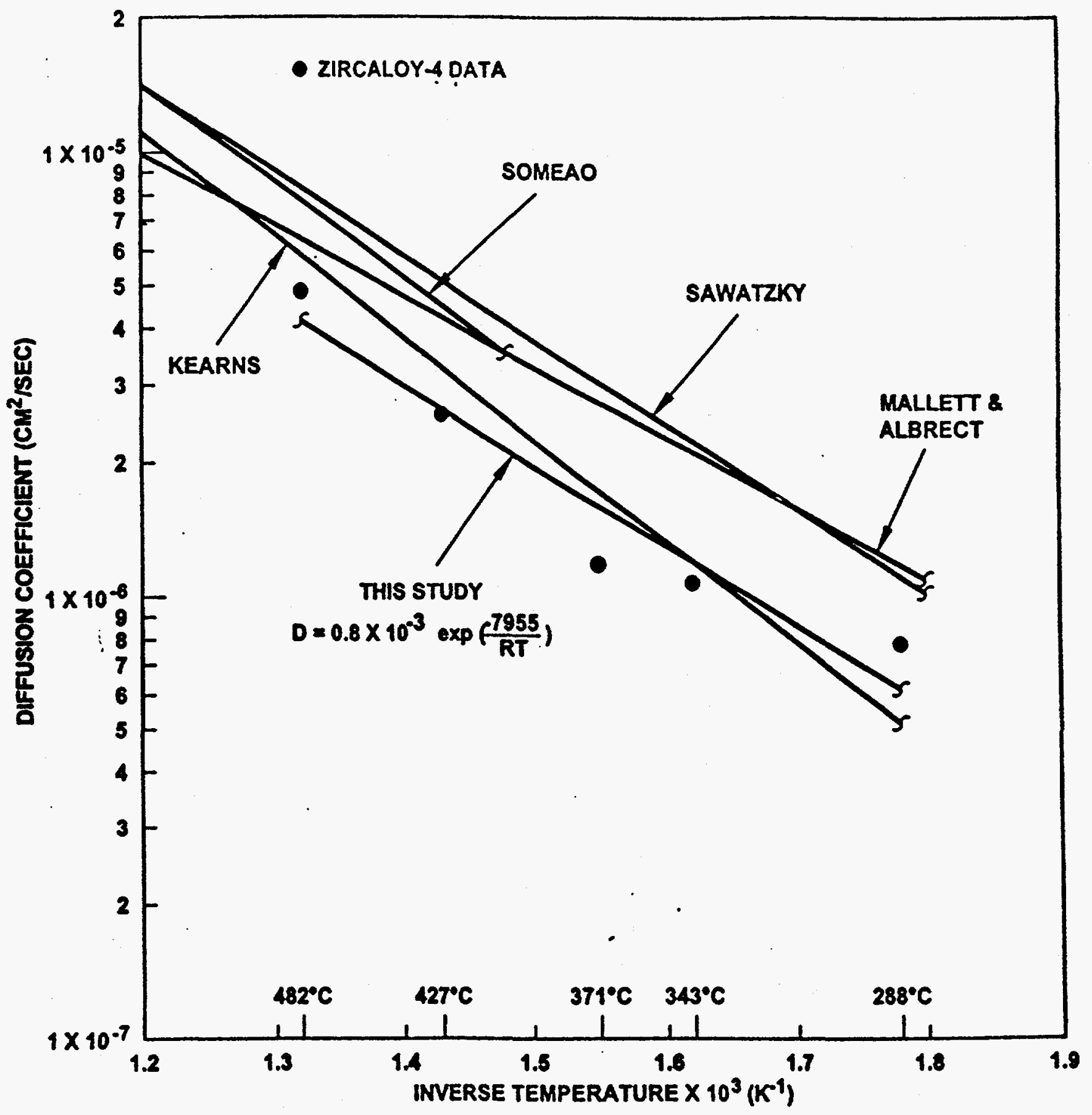

Flgure 13 Diffusion Coefficient of Hydrogen in Alpha-Zirconlum as a Function of Temperature 


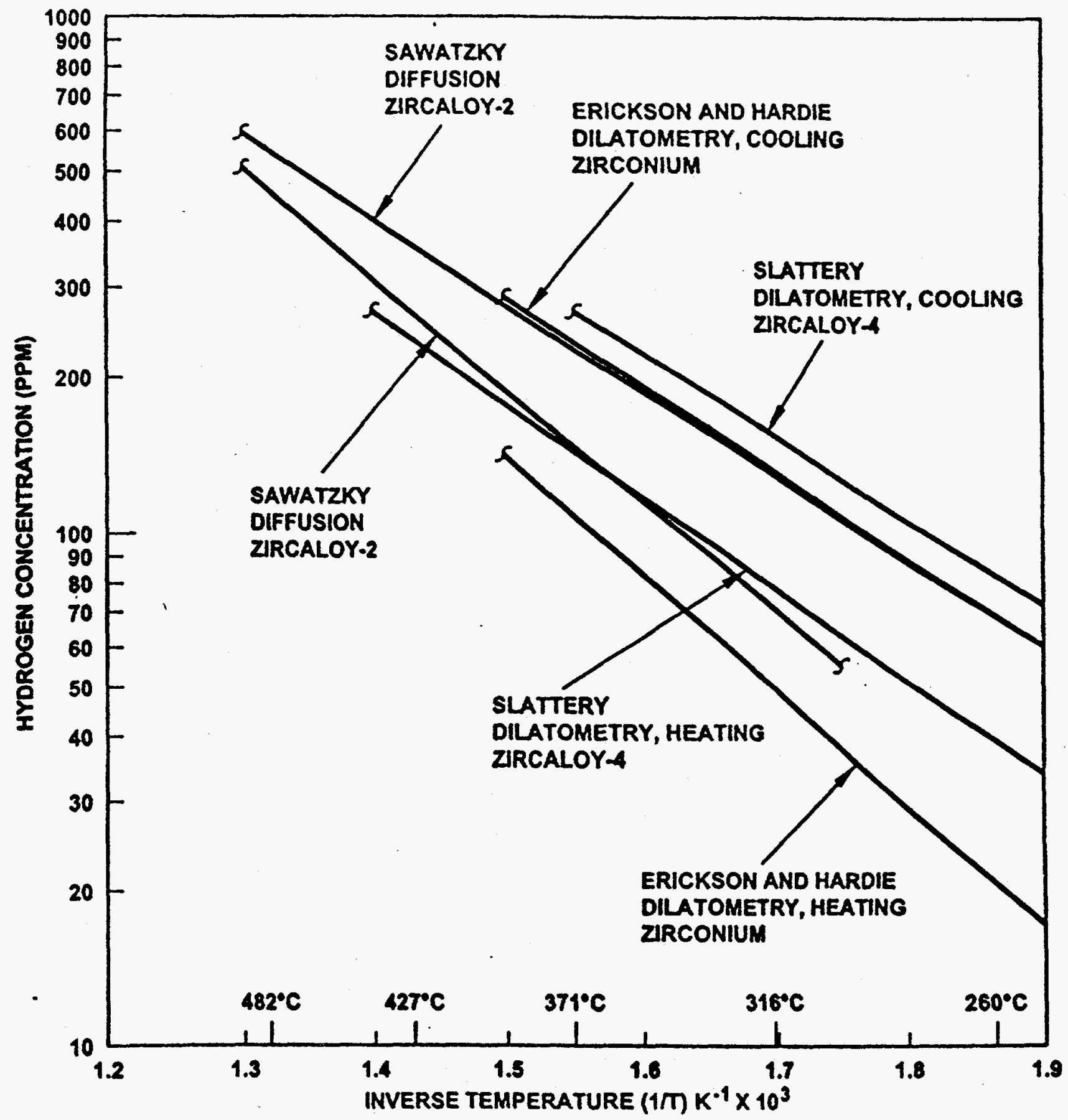

Figure 14 Hydrogen Solvus in Zirconlum Alloys as a Function of Temperature 
TEMPERATURE UNIFORM ACROSS SAMPLE

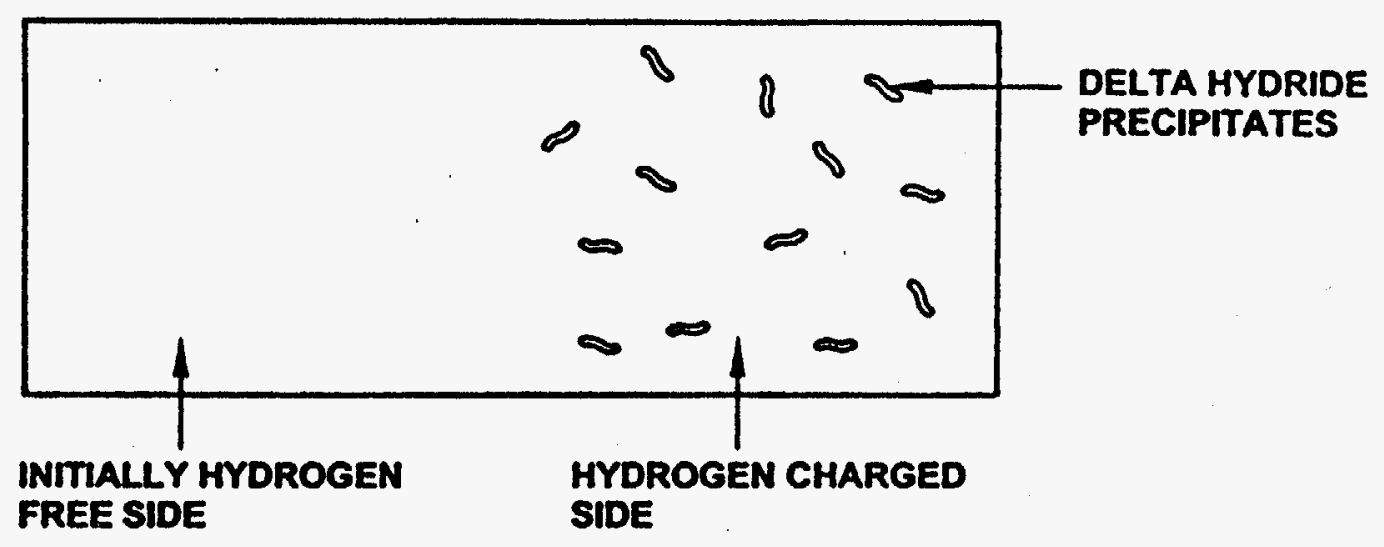

PREANNEAL
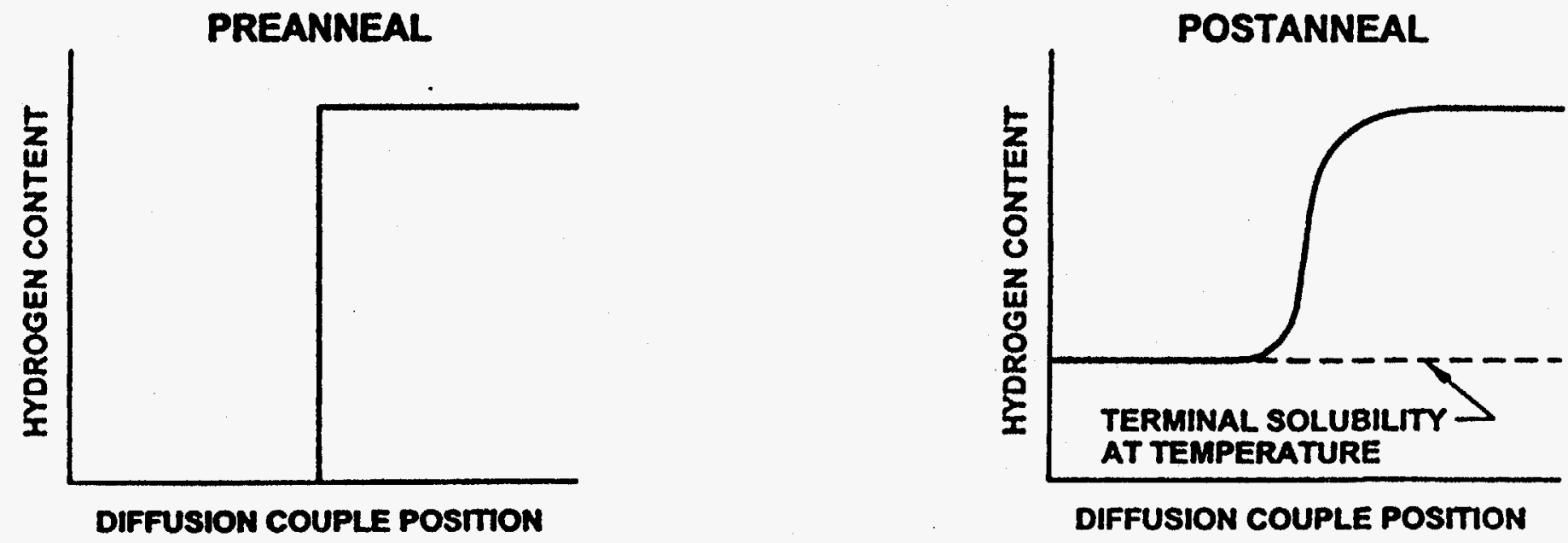

Figure 15 Determination of the Solvus on Dissolution by the Diffusion Method 


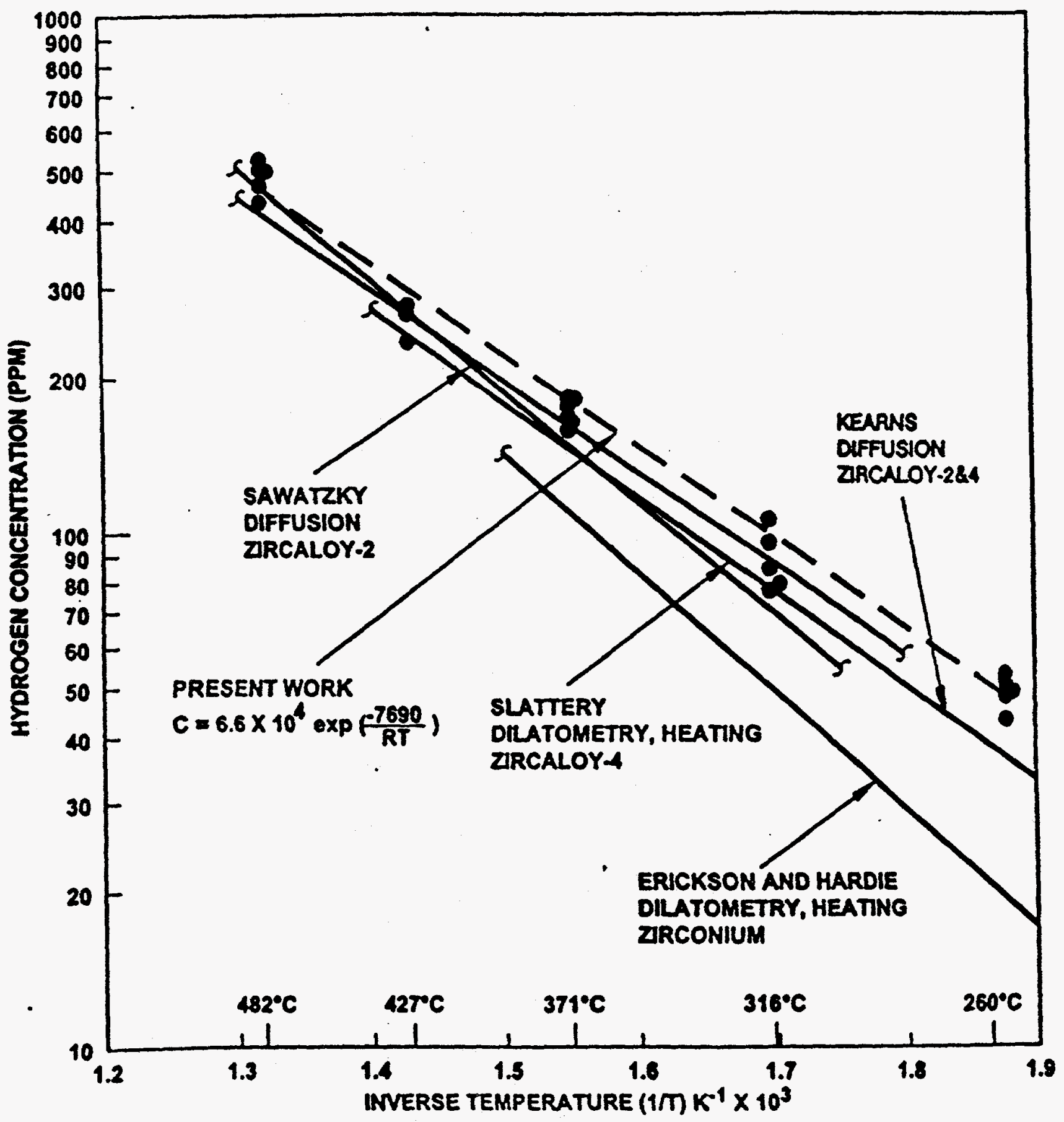

Figure 16 Hydride Dissolution Solvus of Zrconium Alloys as a Function of Temperature 

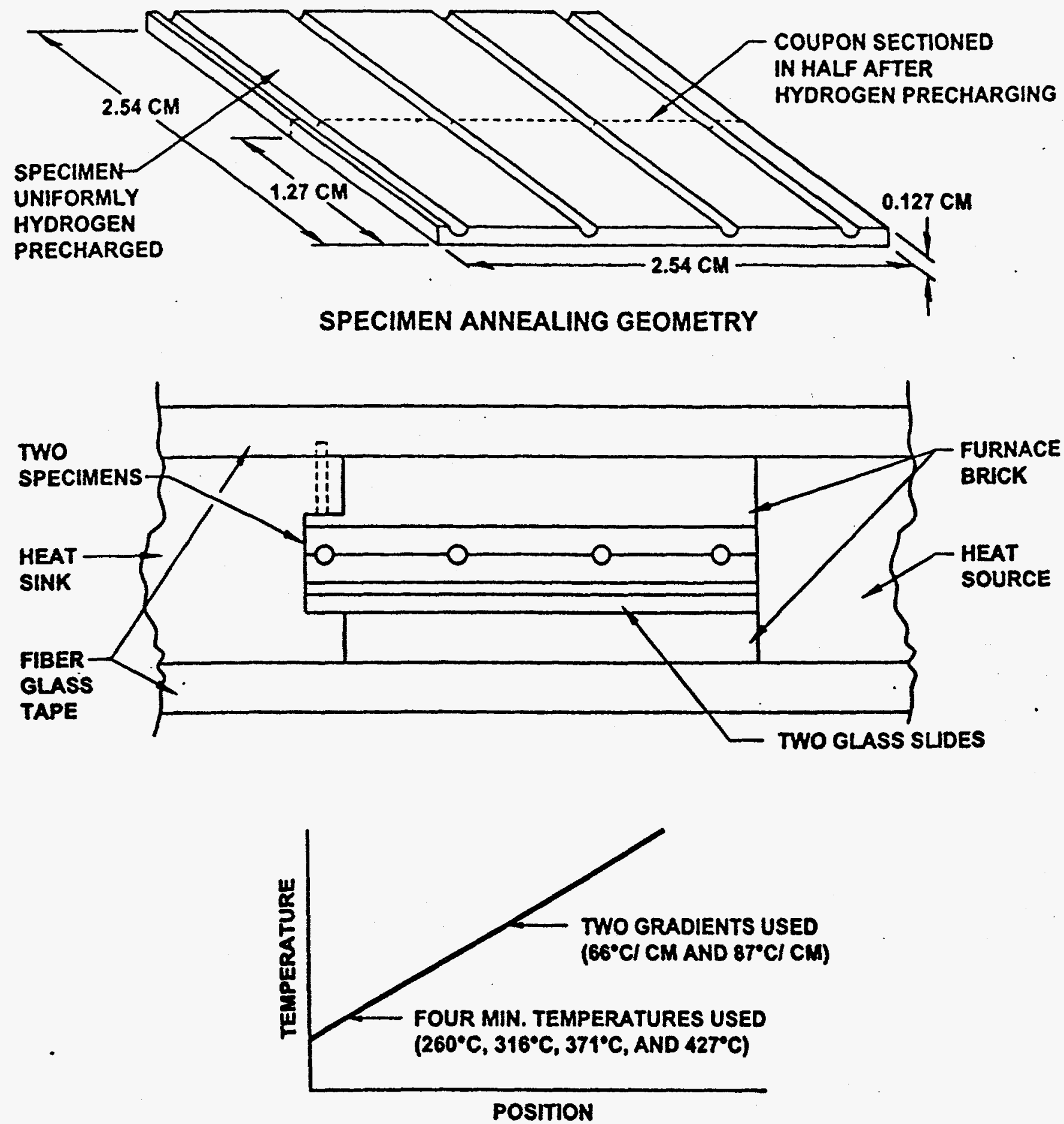

SECTIONING OF SAMPLE FOR HYDROGEN ANALYSIS COLDEND
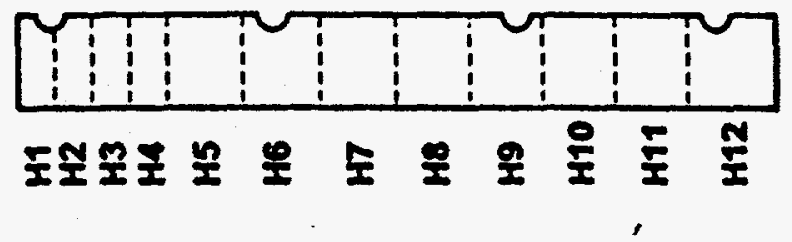

HOT END

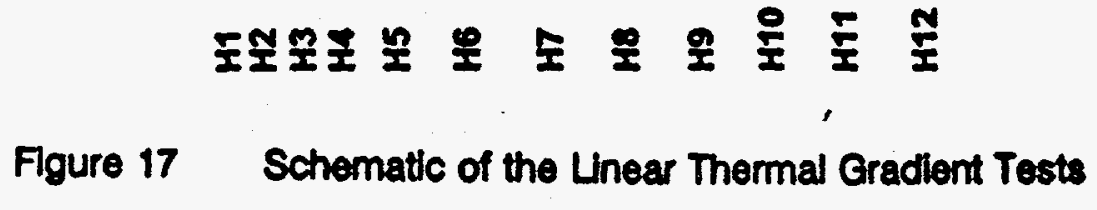




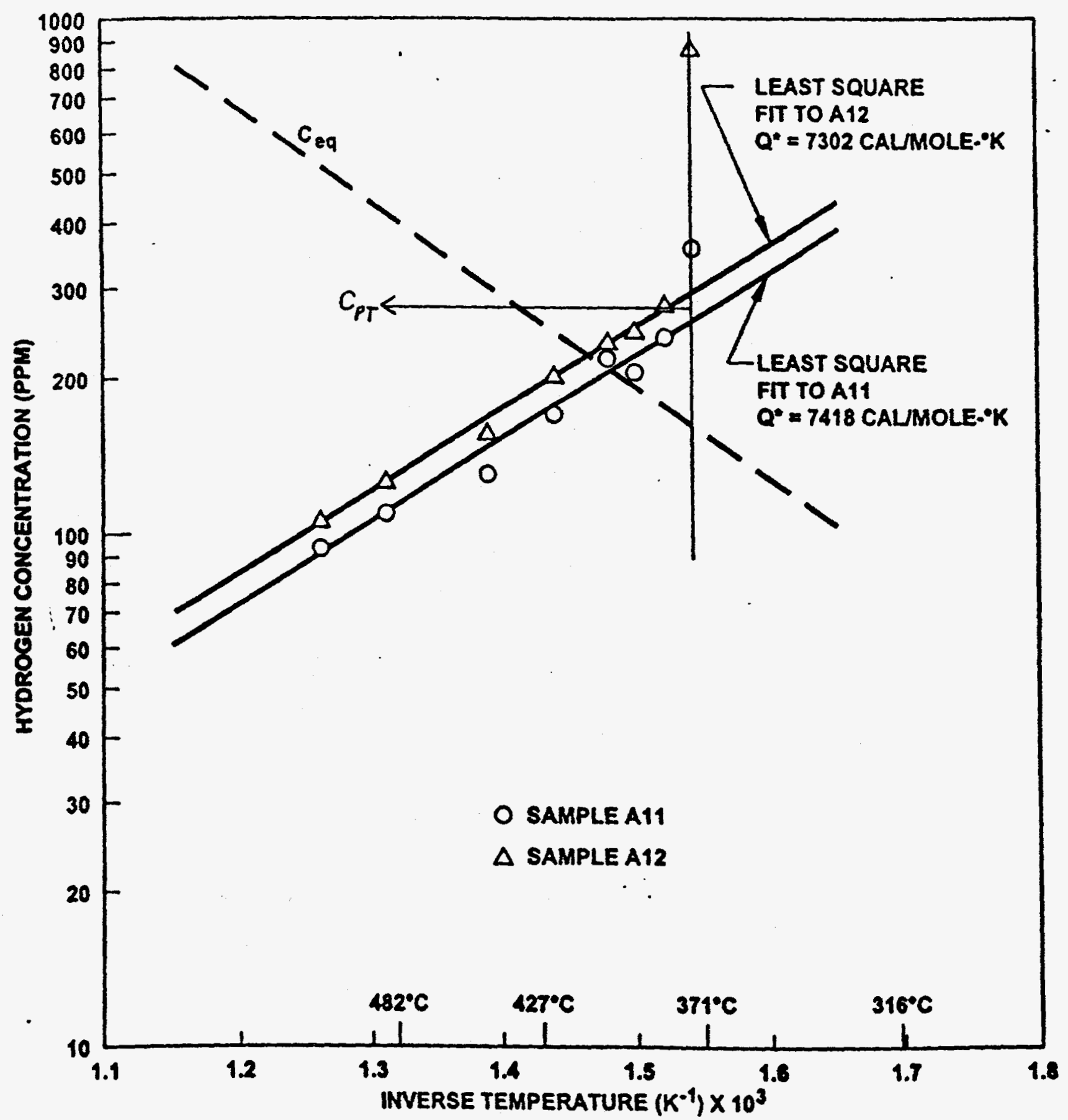

Figure 18 Hydrogen Concentration as a Function of Temperature in a $66^{\circ} \mathrm{C} / \mathrm{cm}$ Unear Thermal Gradlent Test, Cold end at $371^{\circ} \mathrm{C}$ 


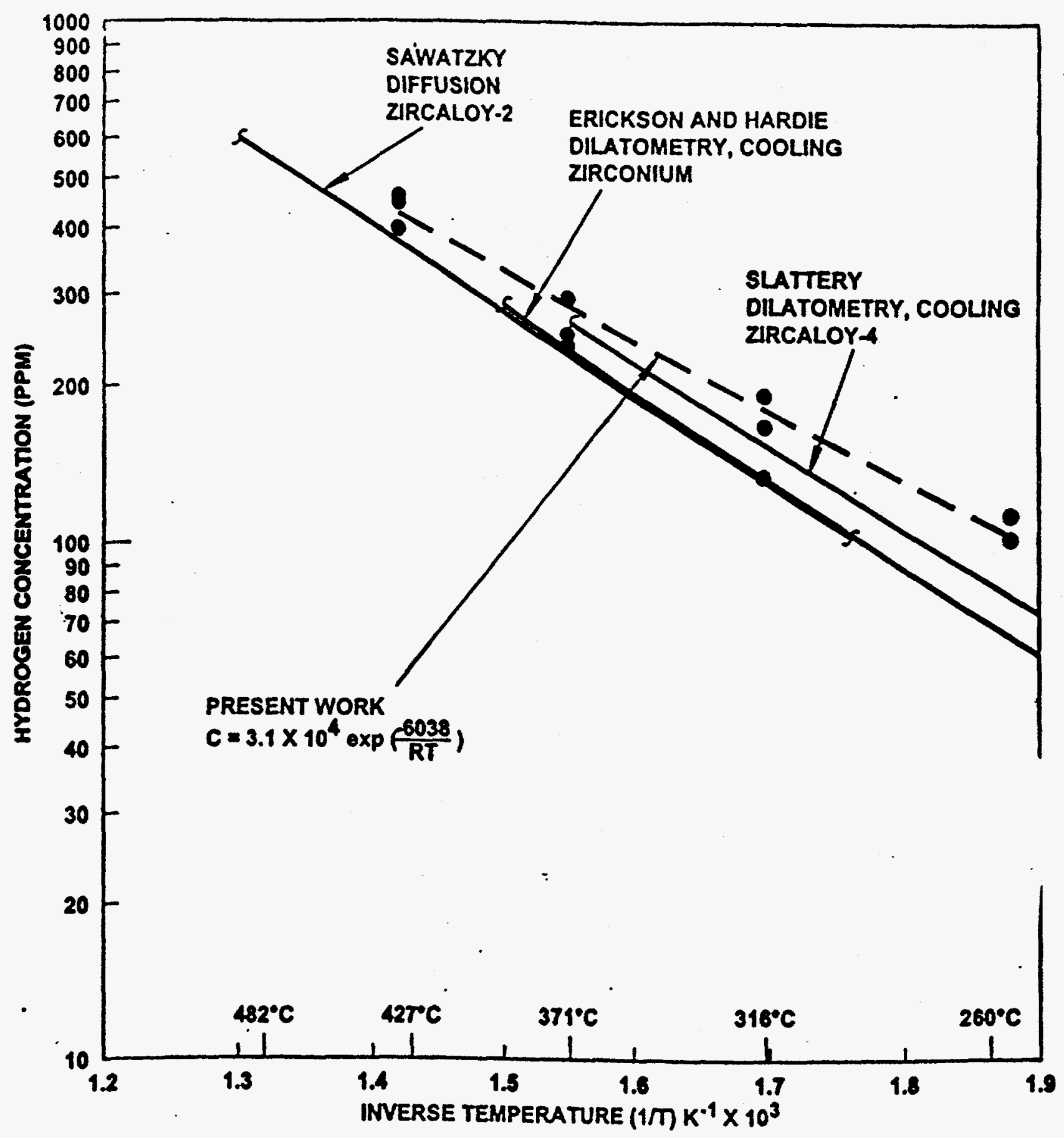

Figure 19 Hydrogen Precipitation Solvus of Zrconium Alloys as a Function of Temperature 


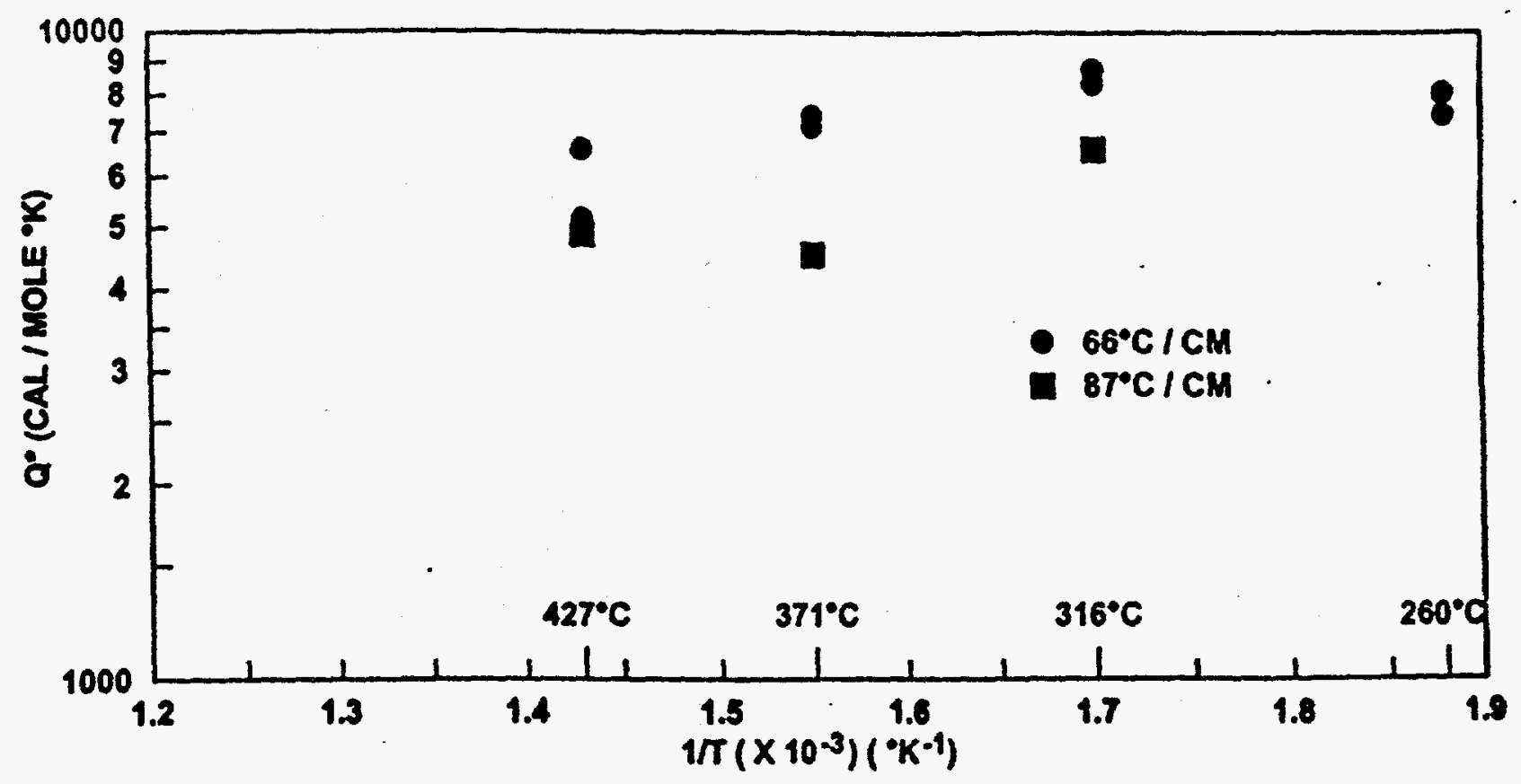

NOTED TEMPERATURE IS COLD TEMPERATURE IN SAMPLES CONTAINING LINEAR THERMAL GRADIENTS OF $300^{\circ} \mathrm{F}$ I INCH AND $400^{\circ} \mathrm{F}$ I INCH

Figure 20 Heat of Transport of Hydrogen in Alpha-Annealed Zircaloy-4 as a Function of Temperature 
SUPERCHARGING OF ISOTHERMAL CORROSION COUPONS REF. (28)
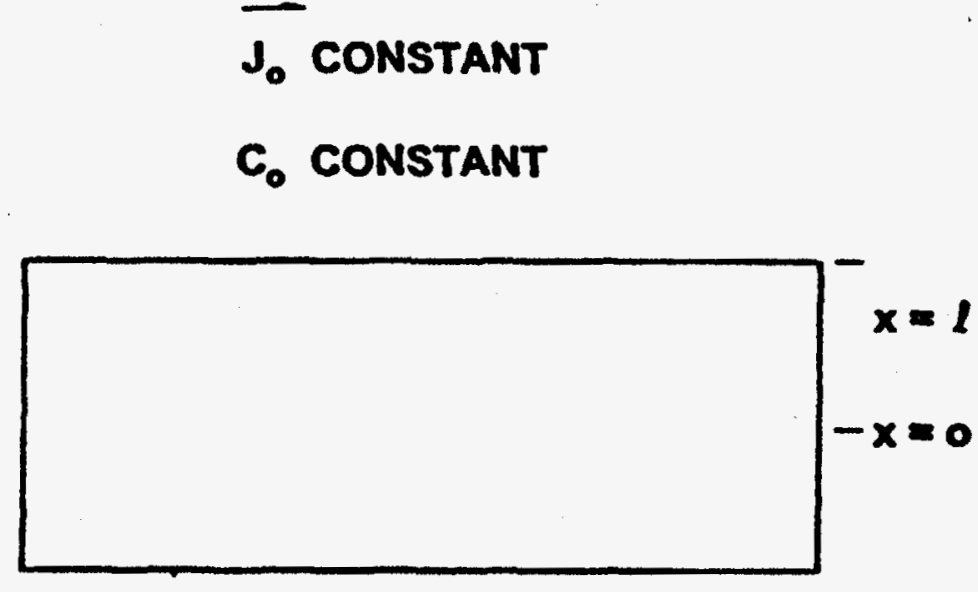

$$
M_{p p m}=\frac{J_{e} l \alpha}{D^{1 / 2}} \quad \frac{\cosh \left(\frac{\alpha x}{D^{1 / 2}}\right)}{\sinh \left(\frac{\alpha l}{D^{1 / 2}}\right)}
$$

$J_{0}=$ SURFACE HYDROGEN FLUX

$D$ - DIFFUSION COEFFICIENT

$l$ = SPECIMEN HALF THICKNESS

$x=$ DISTANCE FROM MIDPLANE

$M=$ QUANTITY OF HYDROGEN PRECIPITATED

$M X_{1} / M X_{0}=\cosh \left(\alpha \times / 0^{1 / 2}\right)$

Flgure 21 Method Used to Determine the Precipltation Rate Parameter a 


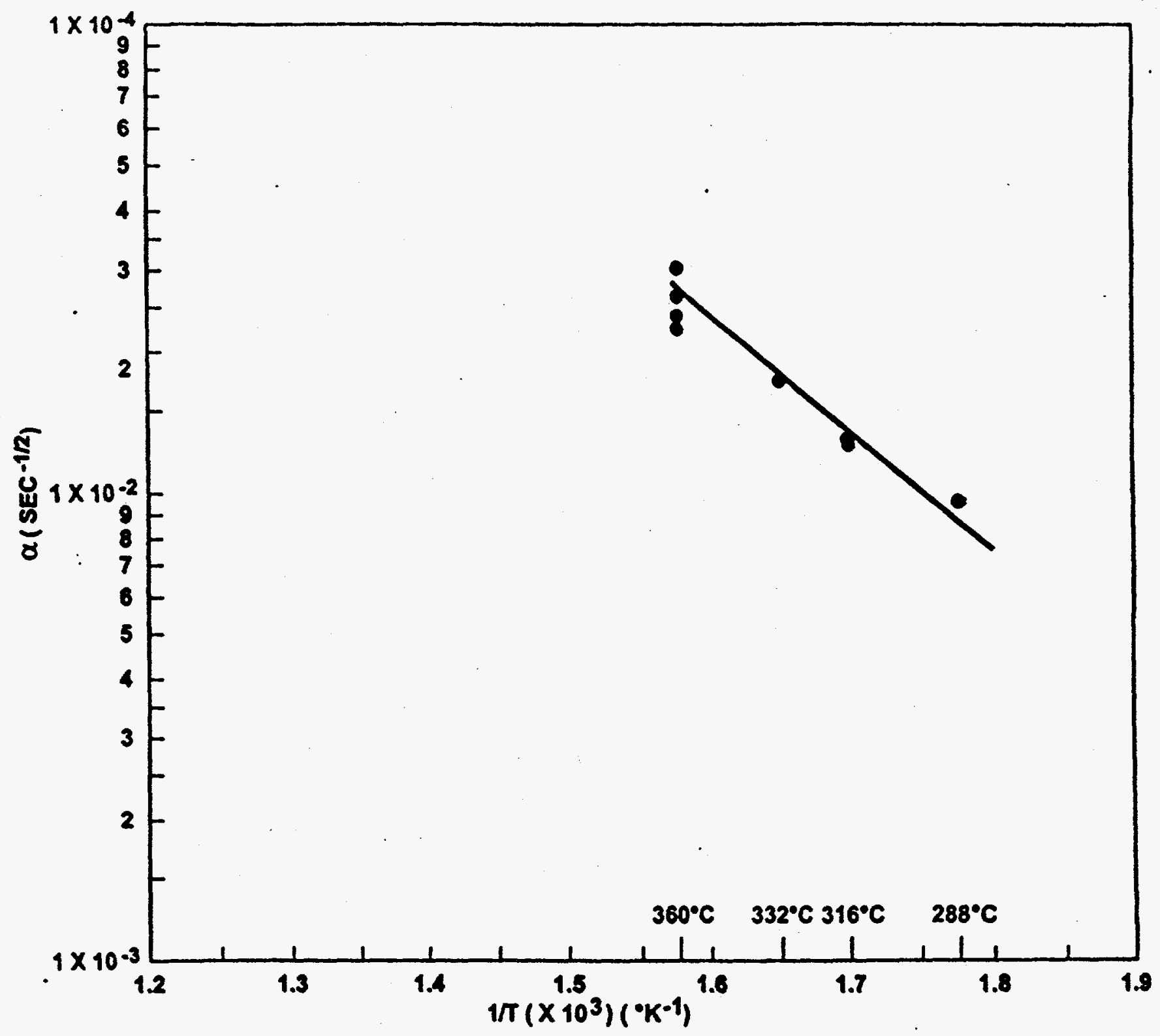

Figure 22 Precipitation Rate Parameter $\sigma$ as a Function of Temperature 


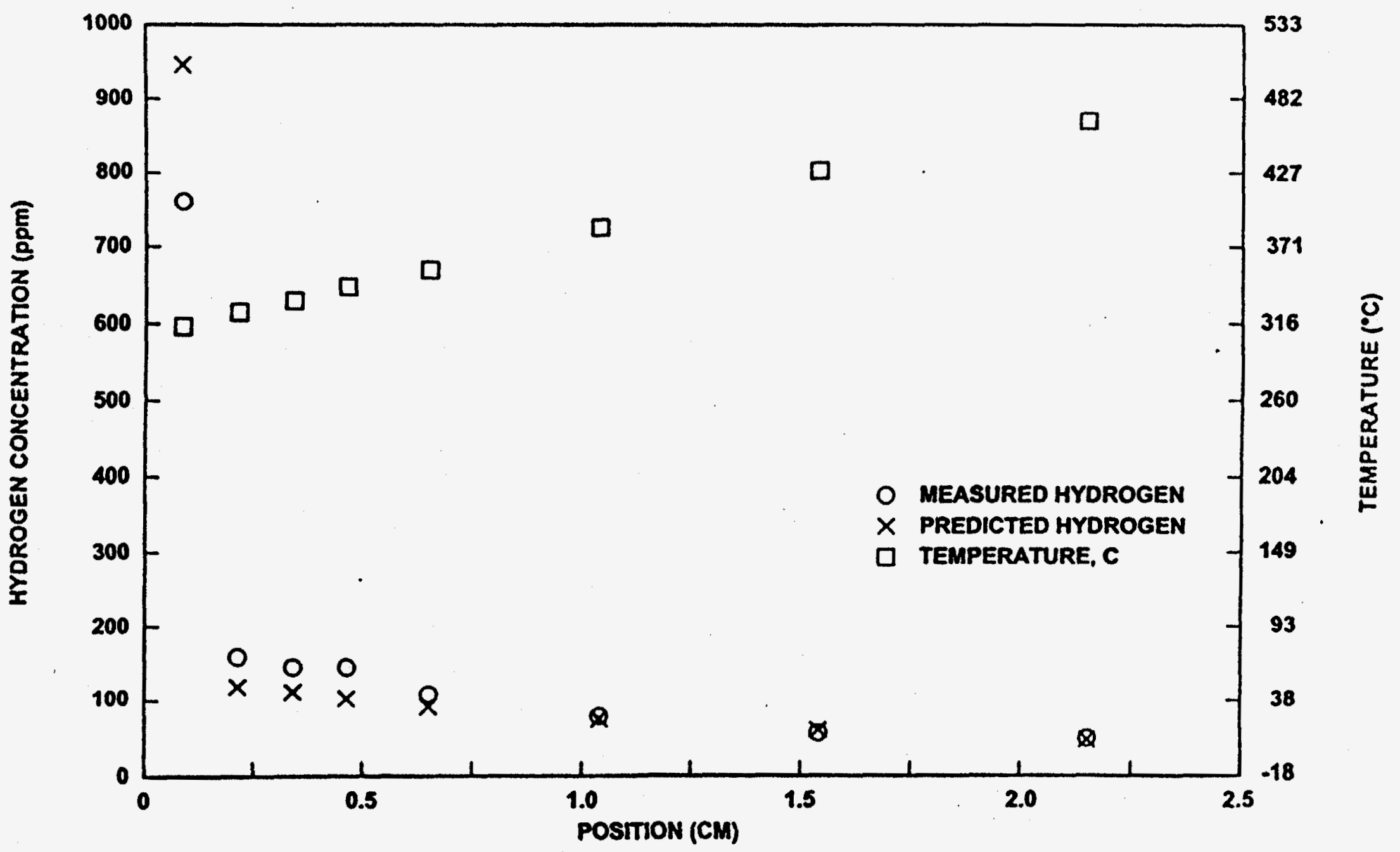

Figure 23

Predicted and Observed Hydrogen Concentration Profile After 30 Days in a Thermal Gradlent 


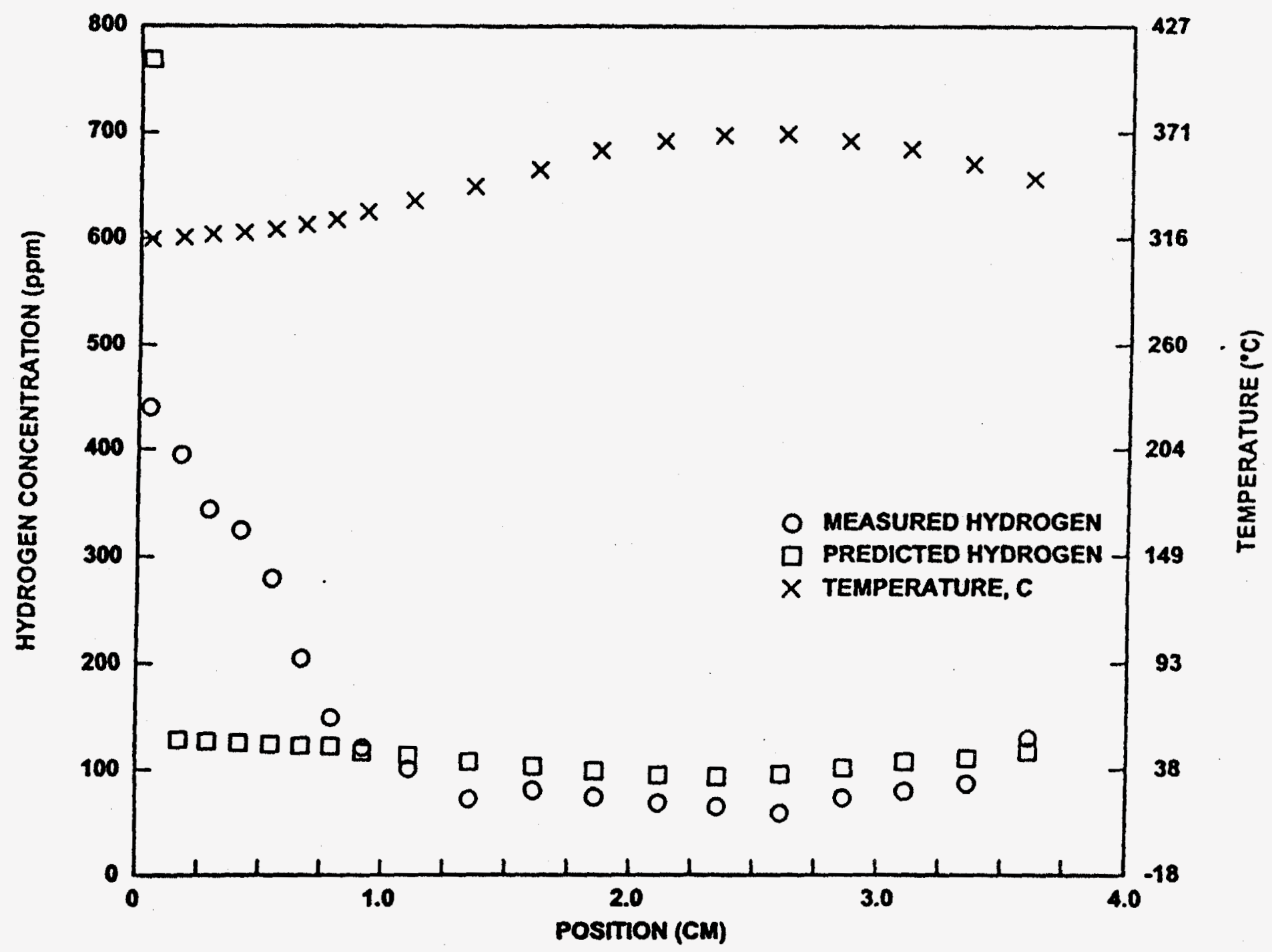

Figure 24 Predicted and Observed Hydrogen Concentration Profile After 200 Days in a Thermal Gradient, Effect on an Internal Temperature Maximum 